\title{
Influence of the Ocean and Greenhouse Gases on Severe Drought Likelihood in the Central United States in $2012^{\mathscr{O}}$
}

\author{
DAVid E. Rupp, SiHAn Li, AND Philip W. Mote \\ Oregon Climate Change Research Institute, College of Earth, Ocean, and Atmospheric Science, Oregon State University, \\ Corvallis, Oregon \\ NEIL MASSEY \\ Environmental Change Institute, School of Geography and the Environment, University of Oxford, \\ Oxford, United Kingdom \\ SARAH N. SparRow AND DAVID C. H. WALlOM \\ Oxford e-Research Centre, University of Oxford, Oxford, United Kingdom
}

(Manuscript received 8 April 2016, in final form 1 November 2016)

\begin{abstract}
The impacts of sea surface temperature (SST) anomalies and anthropogenic greenhouse gases on the likelihood of extreme drought occurring in the central United States in the year 2012 were investigated using large-ensemble simulations from a global atmospheric climate model. Two sets of experiments were conducted. In the first, the simulated hydroclimate of 2012 was compared to a baseline period (1986-2014) to investigate the impact of SSTs. In the second, the hydroclimate in a world with 2012-level anthropogenic forcing was compared to five "counterfactual" versions of a 2012 world under preindustrial forcing. SST anomalies in 2012 increased the simulated likelihood of an extreme summer precipitation deficit (e.g., the deficit with a $2 \%$ exceedance probability) by a factor of 5 . The likelihood of an extreme summer soil moisture deficit increased by a similar amount, due in great part to a large spring soil moisture deficit carrying over into summer. An anthropogenic impact on precipitation was detectable in the simulations, doubling the likelihood of what would have been a rainfall deficit with a $2 \%$ exceedance probability under preindustrial-level forcings. Despite this reduction in rainfall, summer soil moisture during extreme drought was essentially unaffected by anthropogenic forcing because of 1) evapotranspiration declining roughly one-to-one with a decrease in precipitation due to severe water supply constraint and despite higher evaporative demand and 2) a decrease in stomatal conductance, and therefore a decrease in potential transpiration, with higher atmospheric $\mathrm{CO}_{2}$ concentrations.
\end{abstract}

\section{Introduction}

In summer of 2012 large precipitation deficits induced severe drought in much of the contiguous United States (CONUS), with 32 states declaring natural disaster status (U.S. Department of Agriculture; http://www.usda. gov/documents/usda-drought-fast-track-designations080812.pdf). The drought was most severe over the

Supplemental information related to this paper is available at the Journals Online website: http://dx.doi.org/10.1175/ JCLI-D-16-0294.s1.

Corresponding author e-mail: D. Rupp, david.rupp@ oregonstate.edu central United States (Great Plains and Midwest) and reached its greatest intensity during the months of May-August (MJJA), a period that normally brings rain essential to the economy of this important agricultural region (Hoerling et al. 2014). Costs arising from the impact, primarily to agriculture but also other sectors, were estimated at US $\$ 31$ billion, making it the second costliest drought in the United States in the modern era behind the drought of 1988 (US $\$ 40$ billion; adjusted by the consumer price index; Smith and Matthews 2015; NCDC 2016).

The onset of the 2012 drought has been called a "heat wave flash drought" (Mo and Lettenmaier 2015), a phenomenon that develops rapidly in response to high 

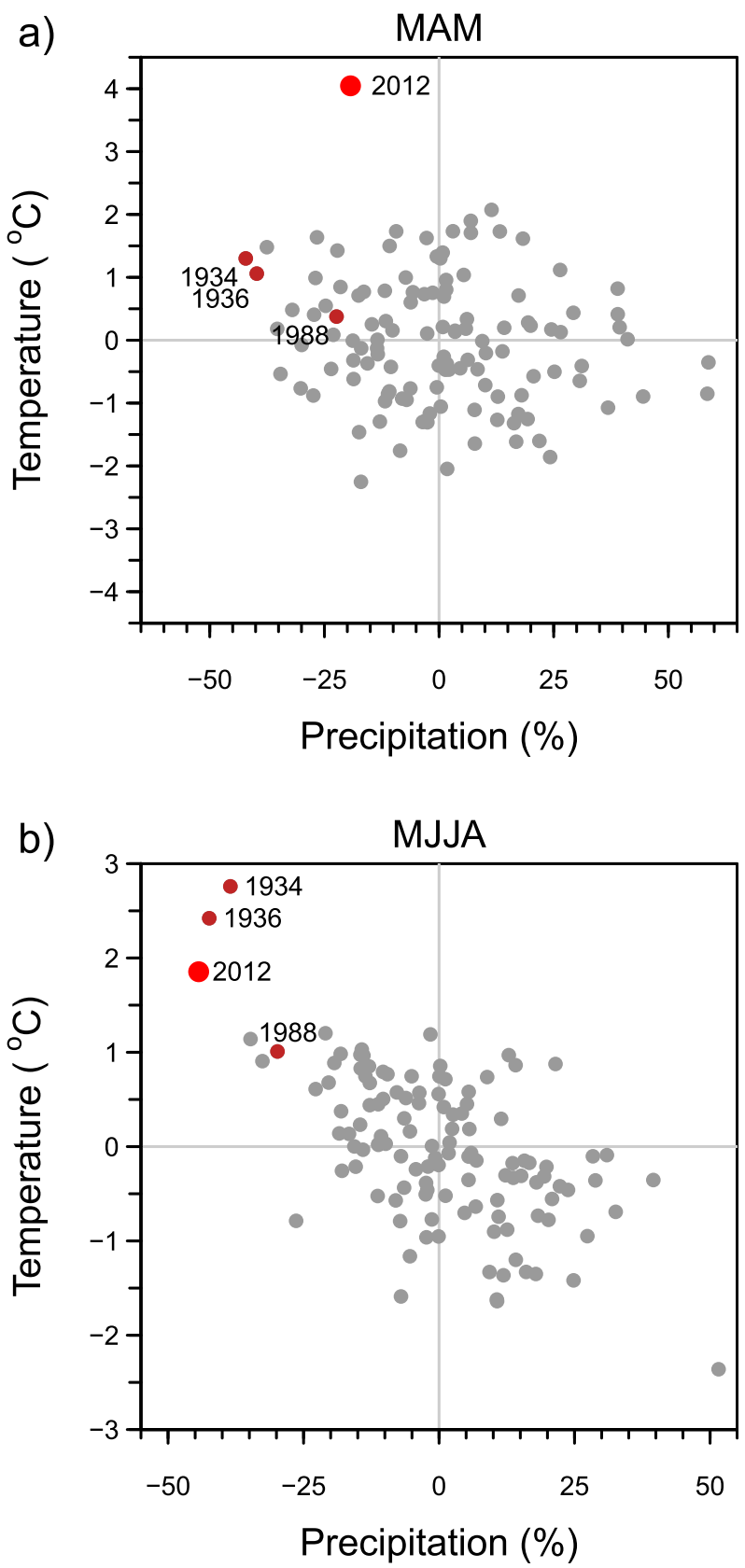

FIG. 1. Observed (a) March-May (MAM) and (b) May-August (MJJA) temperature and precipitation anomalies for the years 1895-2014 averaged over the eight-state region of Colorado, Nebraska, Kansas, Oklahoma, Iowa, Missouri, Arkansas, and Illinois. The reference period is 1895-2014. Data are from the U.S. National Climatic Data Center.

temperatures that increase evapotranspiration and consequently reduce soil moisture. Spring [March-May (MAM)] was extremely warm in the central United States in 2012; the $4^{\circ} \mathrm{C}$ mean temperature anomaly was the highest on record (Fig. 1a), twice as large a departure as the previous record, and 3.9 standard deviations above normal (resulting in a preposterous average return period of $20000 \mathrm{yr}$ if the time series were stationary and the distribution Gaussian). Following the warm spring, the drought intensified through summer because of low rainfall, with continued high temperatures exacerbating conditions through increased evaporative demand.

Hoerling et al. (2014) discuss the atmospheric conditions behind the low rainfall in MJJA 2012. Briefly, a sequence of high pressure ridges over the United States impeded cold fronts from traveling south from Canada into the central United States and suppressed deep convection during May through July, and in August a pressure trough over the Ohio Valley both inhibited moisture transport inland from the Gulf of Mexico and enhanced downward vertical air movement over the Great Plains. The result was a rainfall total $45 \%$ below normal, making it the largest rainfall deficit in $120 \mathrm{yr}$ of record (Fig. 1b), followed by the dust bowl years of 1936 and 1934 in order of intensity.

The prevailing atmospheric conditions were the combined (and interdependent) result of various factors: atmospheric internal variability, the influence of sea surface temperature (SST) patterns leading up to, and during, MJJA, and forcing from anthropogenic greenhouse gases (GHGs), volcanic aerosols, ozone, dust, and so on (Hoerling et al. 2014). One method of separating the influence of these factors is through large ensemble climate modeling in which initial conditions, boundary conditions, and forcings are varied. To help distinguish the response to SSTs and forcings from internal variability, Hoerling et al. (2014) used a 30-member initial condition ensemble of retrospective climate simulations (1979-2012) from two global atmospheric models: 20 members from the National Center of Atmospheric Research (NCAR) Community Atmospheric Model version 4 (CAM4) and 10 from the European Center Hamburg model version 5 (ECHAM5). They concluded that neither SSTs nor increasing GHGs had a significant impact on the 2012 summer precipitation deficit in the Great Plains. Wang et al. (2014) also examined the role of SSTs but using ensembles from the Goddard Earth Observing System Model version 5 (GEOS-5) and similarly found little evidence of SST influence on the summer 2012 precipitation deficit. In contrast, McKinnon et al. (2016) linked a particular North Pacific SST pattern to the pattern of anomalously high pressure over the United States in the summer of 2012.

To estimate the effect of anthropogenic GHGs, Rupp et al. (2013b) used large ensembles from a third model, the Hadley Centre atmospheric model version 3P (HadAM3P), simulating both 2012 boundary conditions and forcings (428 initial conditions) and a "counterfactual" case (182 initial conditions) with anthropogenic GHG 
influence reduced to year preindustrial levels (circa 1900) but with natural forcings kept at 2012 levels. SSTs in the counterfactual case were produced by subtracting an estimate of the anthropogenic warming pattern in the ocean from the observed SSTs during the period of simulation. Of the two cases, the counterfactual case generated more ensemble-average summer precipitation, but the low end of the probability distribution (e.g., precipitation deficits with return periods greater than a few years) did not reveal statistically significant differences in precipitation.

The large-ensemble modeling studies of Hoerling et al. (2014) and Rupp et al. (2013b) seemed to indicate that the increase in GHG concentrations did not consequentially alter the likelihood of extreme summer precipitation deficit in the year 2012. However, in the case of Hoerling et al. (2014), industrial-era emissions would have contributed to their 1981-2010 baseline conditions, so the total anthropogenic GHG influence was underrepresented in the simulations: GHG concentrations (in total $\mathrm{CO}_{2}$ equivalent of all Kyoto Protocol GHGs) increased $56 \%$ by 2012 since 1850 , whereas they were about $11 \%$ higher in 2012 than the average for 1981-2010 (Meinshausen et al. 2011). Furthermore, a strong conclusion could not be drawn from the Rupp et al. (2013b) study because they were unable to quantify the effects of SST uncertainty from their single spatiotemporal pattern of preindustrial SSTs.

Here we reexamine the influences of SSTs and anthropogenic GHGs on the likelihood of intense summer drought in 2012. Like Hoerling et al. (2014) we use retrospective simulations from a global atmospheric climate model, but unlike that study we use a different model and an ensemble size of 100 members per year to explore the influences of the SSTs and forcings in 2012 on that summer's precipitation and soil moisture relative to the recent past (1986-2014). Furthermore, to better separate the anthropogenic GHG signal from SSTinduced variability, we expand on Rupp et al. (2013b) to include five counterfactual scenarios of 2012 with 2012-level natural variability and preindustrial greenhouse gas forcings, each using a different estimate of the anthropogenic effect on SSTs.

In addition to precipitation and soil moisture, some proximate drivers of these variables are investigated. For example, we examine winds at constant pressure levels, which are expected to be more reliably simulated than convective precipitation that relies on convection and cloud parameterizations whose efficacy is uncertain. These parameterizations have been evaluated for how they reproduce the general global pattern of precipitation but not specifically summer precipitation in the United States (e.g., Pope et al. 2000). Given the challenges in simulating convective precipitation itself
(Boucher et al. 2013), we also examine the propensity for deep convection to occur using a proxy of convective inhibition (CIN), which is the energy required to lift an air parcel vertically from its originating level to its level of free convection (LFC). Myoung and NielsonGammon (2010a,b) found CIN to be more tightly linked to summer precipitation in the studied region than total column water vapor or convective available potential energy (CAPE). Last, we examine evaporative demand by means of the vapor pressure deficit (VPD), given VPD's strong dependency on temperature.

\section{Data and methods}

Measured monthly temperature and precipitation for the years 1895-2014 came from the U.S. National Centers for Environmental Information (NCEI), formerly known as the National Climatic Data Center (NCDC; ftp://ftp.ncdc.noaa.gov/pub/data/cirs/), for the eight states that were strongly afflicted by the drought: Colorado, Nebraska, Kansas, Oklahoma, Iowa, Missouri, Arkansas, and Illinois. For the purposes of this study, we refer to these eight states collectively as the "central United States." Monthly mean wind velocities and temperature at several pressure levels were obtained from the National Centers for Environmental Prediction (NCEP)-National Center for Atmospheric Research (NCAR) Reanalysis 1 (hereinafter simply NCEP; Kalnay et al. 1996).

We used the UK Met Office's HadAM3P atmospheric circulation model (Pope et al. 2000; Gordon et al. 2000; Massey et al. 2014) $\left(1.875^{\circ} \times 1.25^{\circ}, 19\right.$ levels, 15 -min time step) with the Met Office Surface Exchange Scheme 1 (MOSES1; Cox et al. 1999) to simulate the atmospheric and land surface climate from December 2011 through November 2012 under six scenarios, all sharing identical solar irradiance and volcanic aerosols. All six had unique sets of SST boundary conditions, and the first scenario differed from the other five in its anthropogenic atmospheric forcing and sea ice extent. The first scenario ("all forcings") used observed GHG, $\mathrm{O}_{3}$, and nonvolcanic $\mathrm{SO}_{2}$ concentrations and observationbased SSTs and sea ice fractions from the Operational Sea Surface Temperature and Sea Ice Analysis (OSTIA; Donlon et al. 2012). The remaining five scenarios ("natural forcings") used preindustrial GHG, $\mathrm{O}_{3}$, and $\mathrm{SO}_{2}$ concentrations, with five estimates of anthropogenic SST warming removed from the observation-based SSTs.

The anthropogenic effect on SSTs was estimated using a type of delta method following Schaller et al. (2014) wherein the differences in SSTs (the "deltas") for each grid cell and each month - respecting the seasonal cyclewere calculated between a decade that experienced 
TABLE 1. List of CMIP5 models used to calculate changes (deltas) in SSTs. The first ensemble member is used for each model. (Expansions of acronyms are available online at http://www.ametsoc.org/PubsAcronymList.)

\begin{tabular}{ll}
\hline \hline \multicolumn{1}{c}{ CMIP5 model } & \multicolumn{1}{c}{ Delta SST method } \\
\hline CESM1-CAM5.1-FV2 & 1990-2000 historical minus 1990-2000 historicalNat \\
CNRM-CM5 & $1990-2000$ historical minus 1855-65 historical \\
HadCM3 & $1990-2000$ historical minus 1864-74 historical \\
HadGEM2-ES & 2002-12 historical combined with RCP8.5 minus 2002-12 historicalNat \\
INM-CM4 & $1990-2000$ historical minus 1855-65 historical \\
\hline
\end{tabular}

anthropogenic forcing and a decade that did not. The deltas were calculated from SSTs from five global climate models (GCMs) in phase 5 of the Coupled Model Intercomparison Project (CMIP5): CESM1-CAM5.1-FV2, CNRM-CM5, HadCM3, HadGEM2-ES, and INM-CM4. HadGEM2-ES and INM-CM4 were chosen because they are among the CMIP5 models showing the highest and lowest transient climate responses, respectively (Forster et al. 2013; see also Table S1 in the online supplementary material), whereas CNRM-CM5 falls near the average. HadCM3 was chosen because it contains the atmospheric model used in this study (HadAM3), although with some modifications. Last, CESM1-CAM5.1FV2 was selected arbitrarily to increase the sample size.

Because the CMIP5 archive was not complete when the SST forcing files were created, not all SST patterns were calculated the same way. If available, the "historical" scenario and "historicalNat" scenario were used, representing all observed atmospheric forcings and only natural observed atmospheric forcings, respectively (Taylor et al. 2012). Table 1 summarizes the method used for each GCM. The decadal-average SST differences were then spatially smoothed with a Gaussian filter (standard deviation of filter window $=1$ grid cell longitude $\times 2^{-1 / 2}$ grid cells latitude) and subtracted from the observed 2012 OSTIA SSTs.

The differences in SST from the all-forcings to the natural-forcings scenarios, averaged over December 2011-August 2012 and $70^{\circ} \mathrm{S}-70^{\circ} \mathrm{N}$, were $-0.31^{\circ},-0.42^{\circ}$, $-0.41^{\circ},-0.69^{\circ}$, and $-0.34^{\circ} \mathrm{C}$ for CESM1-CAM5-1FV2, CNRM-CM5, HadCM3, HadGEM2-ES, and INM-CM4, respectively. Supplemental figures S1 and S2, respectively, show the spatial patterns of the differenced SSTs imposed on the OSTIA observations and the 2012 SST anomalies averaged by season in each scenario. The final delta SSTs at any grid cell can be considered to be a combined result of a GCM's simulated global transient climate response, its local response, and its internal variability. While the decadal average reduces the influence of internal variability at time scales of one to a few years, variability at longer time scales-such as that expressed by, for example, the Pacific decadal oscillation (PDO)—remains.
This will be a consideration in the interpretation of the results.

The five natural-forcings scenarios described above used an identical sea ice fraction to constrain the question to one of SST uncertainty and because SST variability is expected to have a much stronger influence over central U.S. climate than sea ice variability (e.g., Rupp et al. 2015). Sea ice fraction was taken from HadISST1 (Rayner et al. 2003) for the period December 1968-November 1969, following Rupp et al. (2015). This period was chosen because it had the largest mean annual Arctic sea ice extent in the HadISST1 record (although not the largest Antarctic extent). The net increase in Arctic sea ice extent in the natural-forcings scenarios above the observed December 2011-August 2012 sea ice was $19 \%, 14 \%$, and $86 \%$ in winter [December-February (DJF), spring (MAM), and summer [June-August (JJA)], respectively.

Because we were interested in comparing soil moisture across all scenarios, it was convenient to have all simulations begin with the identical land surface initial condition. By doing so, we neglected the effect of different forcing scenarios on the climatological mean state, or mean tendency, of the terrestrial water storage (water and snow) on 1 December 2011. However, a related experiment examining Texas in summer 2011 indicated that the differences in simulated temperature and precipitation due to varying the initial land surface conditions on 1 December were smaller than the differences due to varying the SST patterns (Rupp et al. 2015). Land surface initial conditions were taken from the final conditions from a simulation of the prior year (December 2010 November 2011) using the all-forcings configuration.

Finally, to generate a large ensemble of simulations per scenario, the baseline initial conditions of the atmospheric potential temperature field were perturbed by adding next-day differences, scaled by different amplitudes and generated from a single year of simulation [see Massey et al. (2014) for details]. We received simulations using 742 to 834 sets of initial conditions per scenario from remote volunteers' computers as part of the Climateprediction.net program (Massey et al. 2014; Mote et al. 2015). 
Model output and derived variables were spatially averaged over the 66 model grid cells that fell within the study area and were area-weighted proportionally using the cosine-of-latitude approximation. What we call "conditional" return periods were calculated for each season, for each variable, and for each forcing ensemble. The return periods are conditional in that they are dependent on the particular sequence of SST patterns and forcings leading up to the time period of interest. Bootstrapping (resampling with replacement) was used to estimate confidence intervals.

To form a baseline with which to compare the 2012 values, statistics of simulated variables over the period December 1985-November 2014 were calculated from an ensemble of simulations using HadAM3P with observed forcing and OSTIA SST and sea ice fractions. Each year contained 100 ensemble members with perturbed initial conditions.

The value of soil moisture that was saved from the HadAM3P simulations is a total column plant-available soil moisture. It is the unfrozen soil moisture above the wilting point that is weighted by a root density fraction term that decreases exponentially with depth through the four soil layers in MOSES1. Roots are limited to the top $1 \mathrm{~m}$ (top three layers) for grasses and top $3 \mathrm{~m}$ (all four layers) for forests. Simulated soil moisture referred to in this paper is this plant-available soil moisture, unless stated otherwise.

Because data limitations (monthly output on only a few vertical levels) precluded calculating CIN directly, we used the simple proxy for CIN (CIN*) from Myoung and Nielsen-Gammon (2010a): the difference between the monthly air temperature $T_{a}$ at a given pressure level and monthly near-surface dewpoint temperature $T_{s, \text { dew }}$. Myoung and Nielsen-Gammon (2010a) identified $700 \mathrm{hPa}$ over the U.S. Great Plains and $850 \mathrm{hPa}$ over much of the Midwest as appropriate pressure levels for $T_{a}$ when calculating CIN*. Because $T_{a}$ at $700 \mathrm{hPa}$ was not saved for the natural-forcings runs, we used $T_{a}$ at $850 \mathrm{hPa}$ over the entire study domain in our proxy. As a test of the effect of using $850 \mathrm{hPa}$ in place of $700 \mathrm{hPa}$, we compared the relationship between precipitation and $\mathrm{CIN}^{*}$ in summer using $T_{a}$ at both pressure levels from the all-forcings runs. The relationships were very similar for both pressure levels (see Fig. S3 in supplementary material) and the correlation between precipitation and $\mathrm{CIN}^{*}$ was even slightly stronger for $850 \mathrm{hPa}$ (correlation coefficient $r=-0.88)$ than for $700 \mathrm{hPa}(r=-0.85)$.

\section{Retrospective simulations (1986-2014)}

\section{a. Mean response in 2012}

For each variable, the simulated ensemble-mean anomaly for 2012 was calculated using all simulations completed by the time of this analysis: an 832 -member ensemble for 2012 and 2900 total years of simulations for the baseline period 1986-2014. The ensemble-mean anomaly is given as a standardized departure (S.D.) in Fig. 2 to compare with results in Hoerling et al. (2014), where the 2012 S.D. is the mean of the 2012 ensemble minus the mean of the 1986-2014 ensemble, all divided by the standard deviation of the 1986-2014 ensemble.

Simulated ensemble-mean precipitation for MJJA 2012 is below the simulated 1986-2014 average over most of CONUS, except in some east coast states and coastal California (Fig. 2a). In the central United States, grid cell anomalies range from -0.6 to -0.4 S.D.: negative but not as extreme as observed anomalies of about -2.0 S.D. [see also Fig. 7 in Hoerling et al. (2014)]. Ensemble-mean soil moisture is also below average over CONUS except for the far southwest United States (Fig. 2b). In the central United States, anomalies range from -1.1 to -0.4 S.D. [Compare this to estimated actual anomalies of $<-1.5$ S.D.; see Fig. 7 in Hoerling et al. (2014)]. From the simulations, the larger soil moisture deficits relative to precipitation deficits are consistent with anomalously warm temperatures in spring and early summer leading to increased evapotranspiration, as also noted by Hoerling et al. (2014) in their analysis. For MJJA 2012, ensemble-mean temperature anomalies are nearly 1.5 S.D. over most of CONUS (Fig. 2c) and range from 1.3 to 1.7 over the central United States. Although not shown here, January-April ensemble-mean temperature anomalies across the central U.S. average 1.3 S.D. Observed temperatures average over these months were the highest in the 120 -yr record, and had a 3.0 S.D.

Although the dominant circulation pattern over the central CONUS varied from month to month during the actual drought (Hoerling et al. 2014), on average during MJJA the Great Plains were under a dome of anomalously high pressure; the associated anticyclonic pattern of wind anomalies at $500 \mathrm{hPa}$ from NCEP are shown in Fig. 3a (see also Fig. S4a for the associated geopotential height anomalies). Similarly, the ensemble-mean simulated response also shows anomalously high pressure and an anticyclonic pattern in the 500-hPa wind anomalies centered over the northern Great Plains (Fig. S4b and Fig. 3c, respectively). An anticyclonic pattern is also evident in the 200-hPa wind anomalies from NCEP and the HadAM3P ensemble (not shown). As with the actual drought, the simulated wind anomalies indicate a tendency for middle- and upper-level winds to direct fronts north through Canada instead of into the central United States, while the high pressure dome suggests a tendency toward subsidence, both contributing to suppression of precipitation in the study region. 
a)

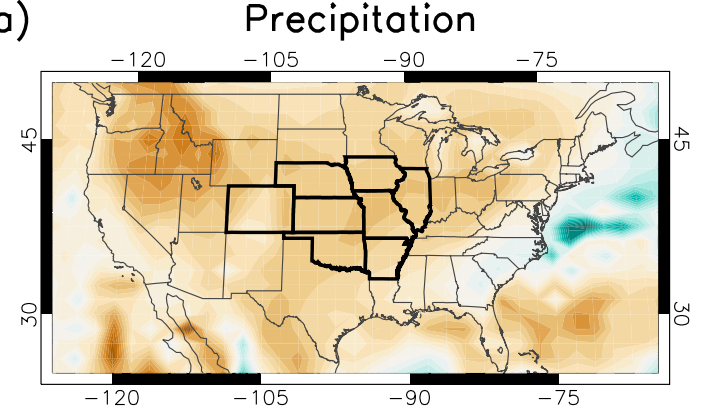

c)
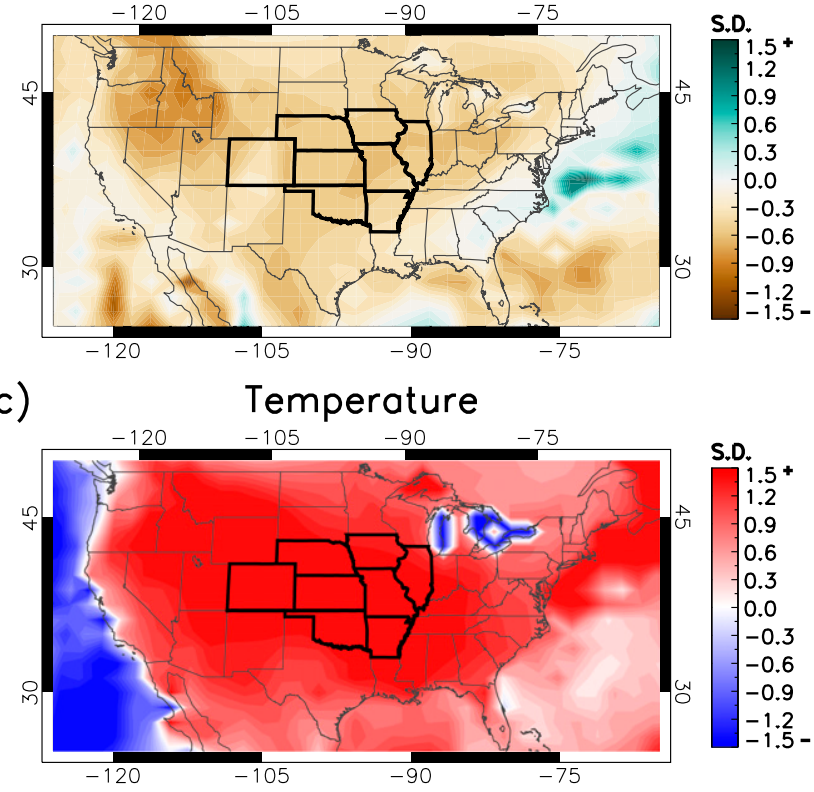

b)

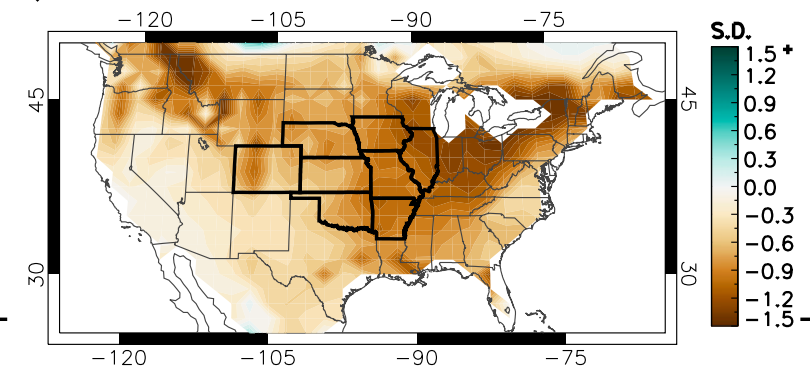

d)

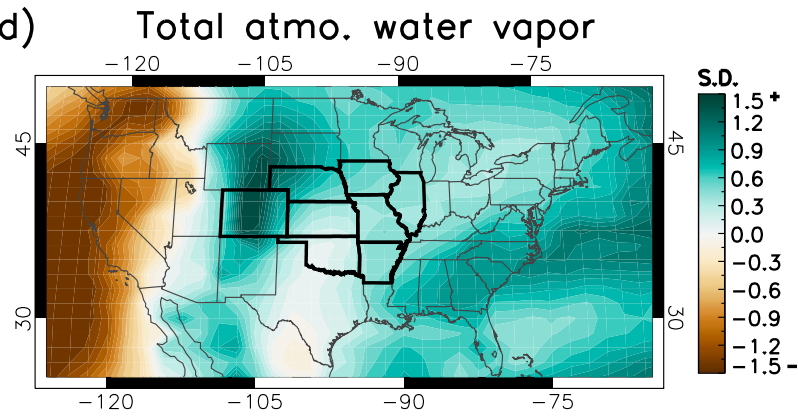

FIG. 2. Simulated May-August 2012 standardized departures (S.D.) of (a) precipitation, (b) soil moisture, (c) 1.5-m air temperature, and (d) total atmospheric water vapor. The 2012 values are the mean of an 832-member ensemble forced with observed SSTs, sea ice, and greenhouses gas concentrations for 2012. The basis for the standardization is the period 1986-2014 with 100 ensemble members per year.

In the actual drought, northeasterly and northerly $850-\mathrm{hPa}$ wind anomalies in the south-central United States indicate that moisture transport from the Gulf of Mexico was inhibited during summer, 2012 (Fig. 3b; see also Hoerling et al. 2014), which also contributed to the drought. In contrast, the simulated ensemble-mean 850-hPa wind anomalies are southeasterly over Texas and southerly over the central Great Plains (Fig. 3d), thus, if anything, implying an increase in water vapor advection into the central United States from the Gulf of Mexico. Simulated total atmospheric column water vapor is also above average in the central United States (Fig. 2d).

Because the GHG concentration (as total $\mathrm{CO}_{2}$ equivalent of all Kyoto Protocol GHGs) was only $8 \%$ higher in 2012 than the average for the period 1986-2014 (Meinshausen et al. 2011), it seems reasonable to conclude that the response to anthropogenic GHGs in 2012 is too small relative to the average response to anthropogenic GHGs over the period 1986-2014 to account for the simulated anomalies in Fig. 2; rather, it is likely that these anomalies result primarily from the SST boundary conditions. Moreover, comparing the 2012 500-hPa wind anomalies in NCEP with those in the HadAM3P ensemble (Figs. 3a,c) suggests that the associated above-average observed pressure dome in NCEP was enhanced by the 2012 SSTs. However, the observed inhibition of water vapor transport from the Gulf of Mexico appears to not be SST-forced but rather due to "random" atmospheric internal variability, based on differences between the reanalysis and HadAM3P 850-hPa winds (Figs. 3b,d).

The strength and spatial extent of the simulated response in Fig. 2 contrasts with Hoerling et al. (2014). In their study, precipitation deficits and soil moisture deficits were largest in the central and southern Intermountain West and small elsewhere, with the Midwest region (Iowa, Missouri, Arkansas, and Illinois) having standardized anomalies between about -0.25 and 0.25 [see Fig. 7, lower row, in Hoerling et al. (2014)]. Unlike the strong CONUS-wide temperature response in our simulations, their largest positive temperature anomalies were in the southwest and along the northeast coast, with anomalies in the Midwest states mostly under 0.5 S.D. Over much of CONUS, the spatial patterns of anomalies simulated by HadAM3P are more consistent with the patterns of observed anomalies [Fig. 7, upper row, in Hoerling et al. (2014)] than the more regionally contained response in Hoerling et al. (2014). However, the HadAM3P-simulated mean response differs conspicuously from observations in the northwest United States where the simulated anomalies are of opposite sign from the observed positive anomalies in precipitation and soil moisture, and negative anomalies in temperature.

\section{b. Change in likelihood of extreme drought in 2012}

Although the above results demonstrate the mean response to the imposed boundary conditions, ultimately 
a)

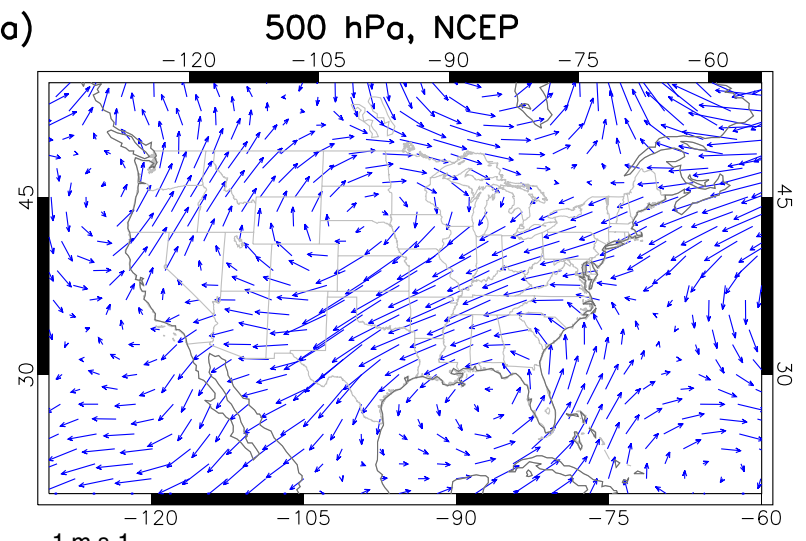

$1 \mathrm{~m} \mathrm{~s}-1 \rightarrow$

c)

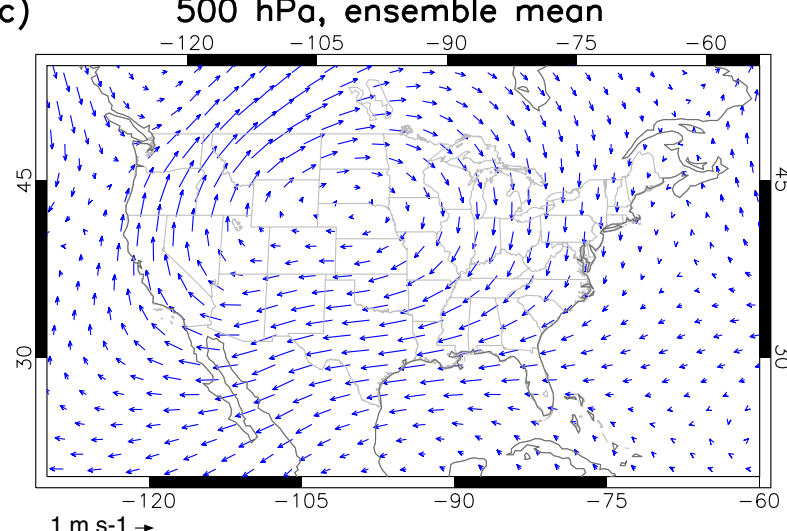

e)

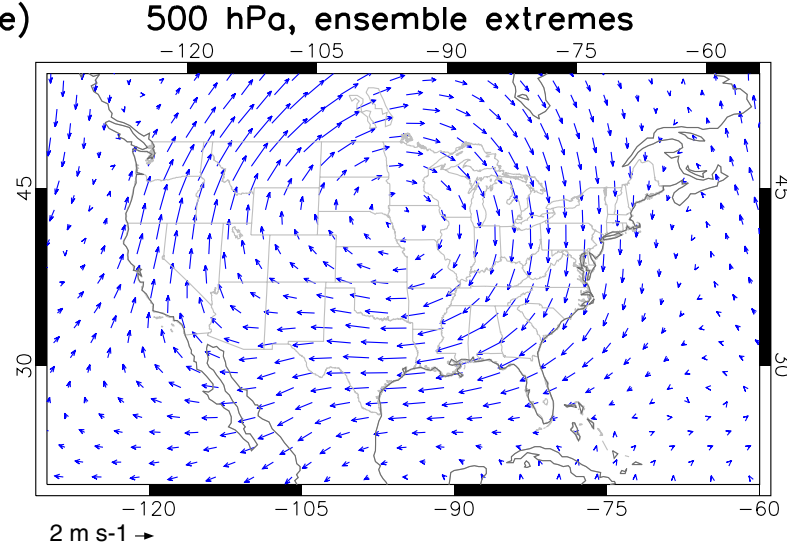

b)

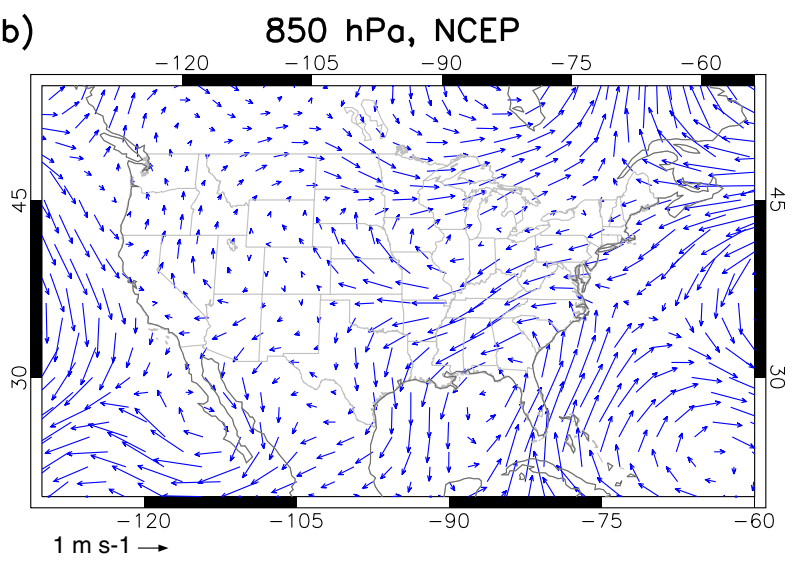

d)

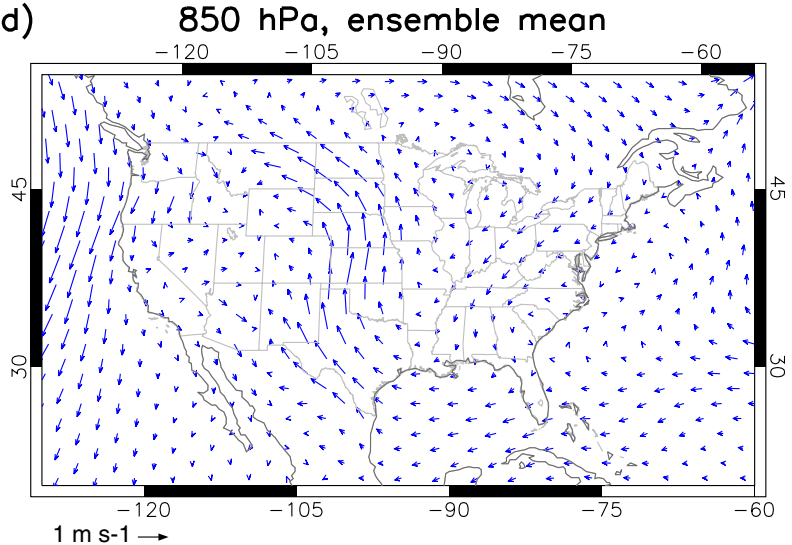

f)

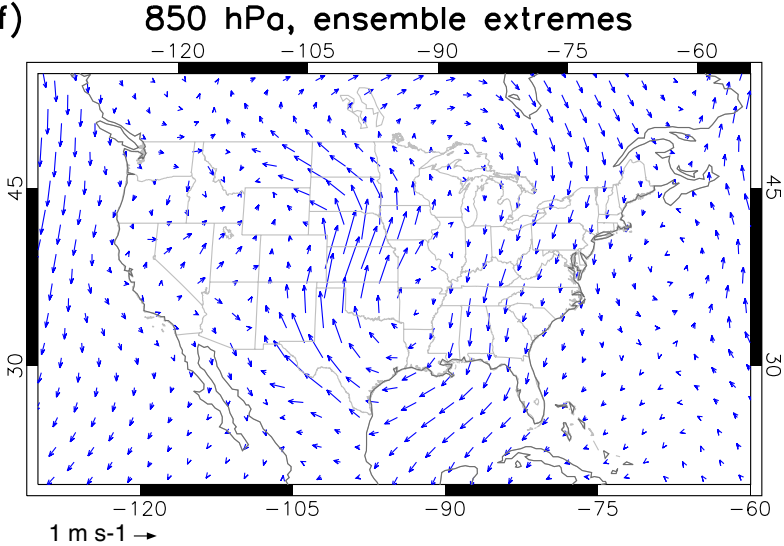

FIG. 3. May-August 2012 wind anomalies from (a),(b) NCEP and (c),(d) the ensemble mean at 500 and 850 hPa, respectively. (e),(f) Change in winds between the average of the ensemble of extreme events for the baseline period and the average of the ensemble of extreme events for the year 2012 at 500 and $850 \mathrm{hPa}$, respectively. The scale of the wind vector differs among panels. See text for detail on the ensembles of extreme events.

our interest is in the response in the tails of the distributions. Probability distributions above the median value are shown here as return period curves, where the return period is the inverse of the probability of a value being exceeded in a given year. Where the lower tail is of primary interest (e.g., for precipitation and soil moisture), we calculate a value as a deficit from the mean, and estimate the exceedance probability of the deficit.

Over the central United States in MJJA 2012 there was a statistically significant shift in the simulated 

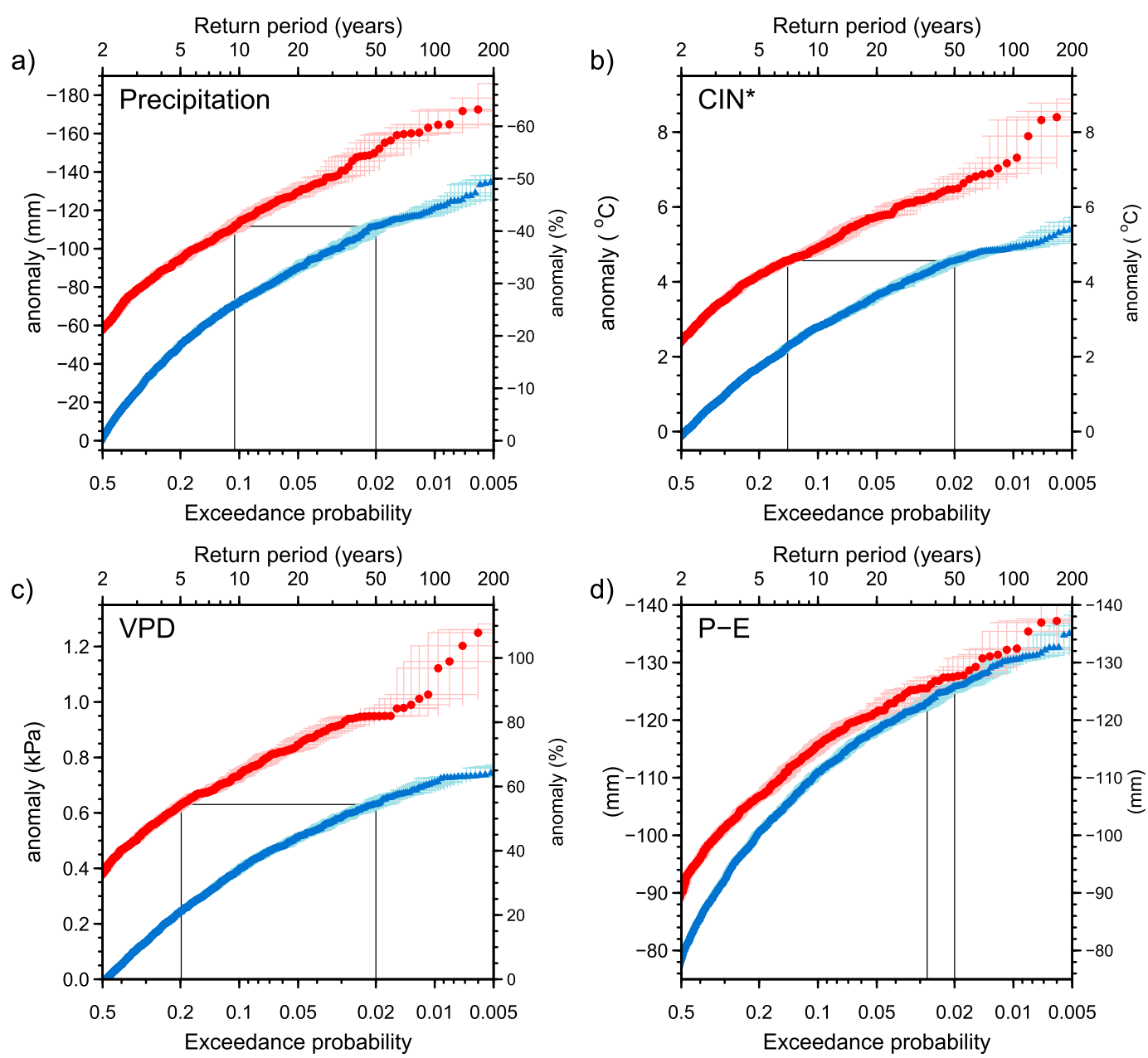

- 2012: 832 ensemble members

4 1986-2014: 100 ensemble members per year

FIG. 4. The 2012-ensemble (red) and 1986-2014-ensemble (blue) exceedance probabilities for domain-averaged MJJA (a) precipitation anomalies, (b) convective inhibition proxy $\left(\mathrm{CIN}^{*}\right)$ anomalies, (c) vapor pressure deficit (VPD) anomalies, and (d) precipitation minus evapotranspiration $(P-E)$. Note that (a) and (d) give return periods on deficits of precipitation and $P-E$, respectively. Note also that $P-E$ values are not given as anomalies. Exceedance probabilities (and associated return periods) are conditional on the forcings and boundary conditions for the associated time period: either 2012 or 1986-2014. Gray lines indicate the probability in 2012 of what would be the 1-in-50-yr event during the period 1986-2014. The reference period for the anomalies is 1986-2014. Thin vertical and horizontal line segments about each point show bootstrapped $90 \%$ confidence intervals.

conditional distribution toward lower precipitation relative to 1986-2014, indicating a significant increase in the likelihood of extreme precipitation deficits in 2012 (Fig. 4a). Although the change in likelihood depends on the precipitation anomaly, we use the event with a 0.02 exceedance probability ( 1 in $50 \mathrm{yr})$ as an example to demonstrate the magnitude of the change. The simulated 0.02 exceedance probability precipitation deficit during the baseline period 1986-2014 equates to a $-40 \%$ simulated anomaly, which is close to the observed percent deficit in 2012. In this example, the 0.02 exceedance probability precipitation deficit during the baseline period corresponds approximately to a 0.1 exceedance probability ( 1 in $10 \mathrm{yr}$ ) in 2012 ; in other words, the likelihood of precipitation being less than $40 \%$ of normal is 5 times greater in 2012 .

To consider whether a change in CIN is a primary factor reducing precipitation in MJJA 2012, we first note the significant shift in the conditional distribution of the convective inhibition proxy (CIN*) in MJJA 2012 toward higher convective inhibition (Fig. 4b). Returning to our example event, the 0.02 exceedance probability CIN* during the baseline period corresponds to about a 0.14 exceedance probability ( 1 in 7 yr) in 2012. Second, 


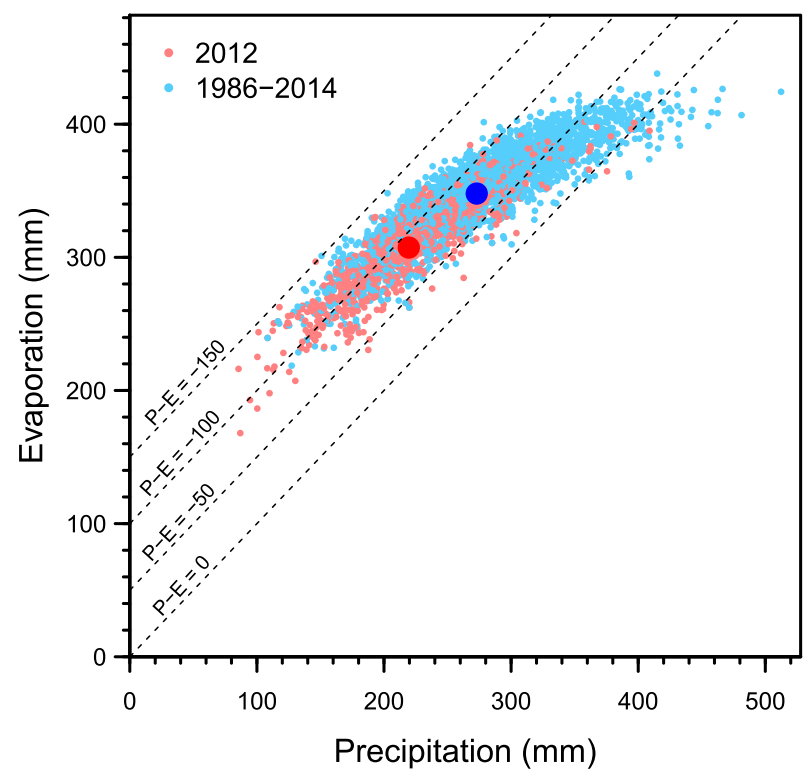

FIG. 5. Domain-averaged simulated MJJA evaporation vs precipitation for the 2012 (pink) and the 1986-2014 ensembles (light blue). The large color-filled circles are the ensemble means.

we note that this change in the exceedance probability for $\mathrm{CIN}^{*}$ outpaces the change in the exceedance probability for precipitation. This difference could be explained by other factors attenuating the effect of CIN on precipitation. Third, we remind the reader of the strong negative correlation of $\mathrm{CIN}^{*}$ and precipitation (Fig. S3). Together, these three points support the hypothesis that the decrease in rainfall is due largely to the increased suppression of deep convection, which more than compensates for any additional moisture coming from the Gulf of Mexico (Fig. 3d).

Primary factors determining evaporative demand at the surface include vapor pressure deficit, shortwave energy flux at the surface, and surface-layer aerodynamic conductance (Dingman 2002). These factors change in MJJA 2012 such that evaporative demand is enhanced relative to the baseline period. The vapor pressure deficit distribution, for one, is shifted higher; e.g., the 0.02 exceedance probability VPD anomaly during the baseline period corresponds to a $0.2 \mathrm{ex}-$ ceedance probability in 2012 (Fig. 4). Net shortwave radiation is also higher, and shows a fivefold increase in likelihood of the baseline value of 0.02 exceedance probability (not shown). Aerodynamic conductance increases as a function of wind speed, and though average wind speed was not saved as a model output, the change in seasonal near surface wind vectors suggests that the prevailing wind pattern merely intensifies, and thus wind speeds increase, in MJJA 2012 (not shown), which would enhance evaporative demand.
Despite the notably higher evaporative demand, precipitation minus evapotranspiration $(P-E)$ in MJJA 2012 is only slightly lower than the mean of the baseline period, and not significantly so for exceedance probabilities greater than 0.05 (Fig. 4d). The reason for the small change in $P-E$ in the lower tail of the distribution is that precipitation and evaporation are tightly correlated in this regime: at progressively drier states, evapotranspiration becomes supply-limited such that evaporation decreases almost one-for-one with decreasing precipitation (Fig. 5). Very roughly, half of the members in the 2012 ensemble fall in this regime where a change in precipitation would be nearly matched by an equal change in evaporation.

The small change in $P-E$ in MJJA 2012 would imply little change in the soil moisture anomaly from the baseline. However, the MJJA 2012 soil moisture distribution is significantly drier than the 1986-2014 distribution (Fig. 6b). While this may at first appear paradoxical, we note that the soil moisture is significantly drier in spring (MAM) 2012 going into summer (Fig. 6a). As stated previously, spring 2012 is much warmer than the baseline period, driving an increase in evapotranspiration, but precipitation in MAM 2012 is also lower than during the baseline period: $11 \%$ lower in the ensemble mean. A consequence is that the $0.02 \mathrm{ex}-$ ceedance probability MAM soil moisture deficit during the baseline period corresponds to a 0.11 exceedance probability ( 1 in $9 \mathrm{yr}$ ) in 2012 . With soil moisture already substantially reduced at the beginning of summer and $P-E$ showing a small decrease, soil moisture remains lower than average through MJJA in the 2012 ensemble.

Last, to examine the response of winds to SSTs during extreme precipitation deficits, we compared the average winds from the most extreme baseline retrospective ensemble members with those from the most extreme 2012 ensemble members. The MJJA study-region precipitation deficit with a 0.02 baseline exceedance probability serves as the cutoff value for both sets of ensembles, yielding 58 (out of 2900) extreme baseline ensemble members and 88 (out of 832) extreme 2012 ensemble members.

These differences in winds at both the 500- and 850-hPa pressure levels (Figs. 3e and 3f, respectively) during low precipitation events show patterns that resemble the 2012 ensemble-mean anomalies (Figs. 3c and $3 \mathrm{~d}$, respectively). At $500 \mathrm{hPa}$, there is a similar anticyclonic pattern centered over the northern Great Plains, although the center of the pattern is located slightly farther east and the wind speed anomalies are roughly doubled in the extreme-event ensemble (note the scale change between Figs. $3 \mathrm{c}$ and 3e). At $850 \mathrm{hPa}$, both the 2012 mean and extremes show a strengthening of the meridional 

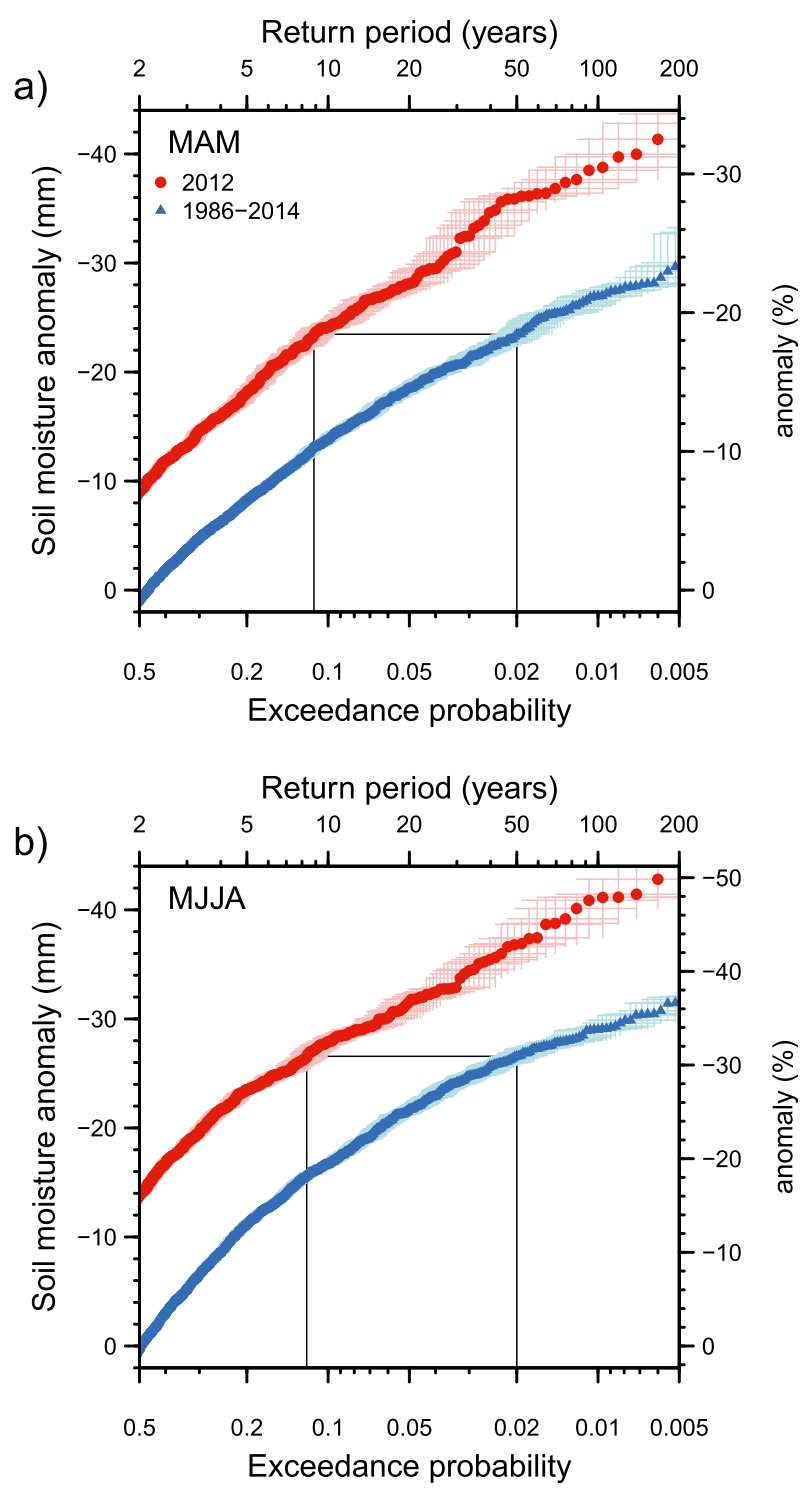

FIG. 6. As in Fig. 4, but for (a) MAM and (b) MJJA soil moisture deficit.

southerly flow across the Great Plains, although the strengthening is greater for the extreme-event ensemble. The similarities in the patterns of the 2012 ensemble-mean anomalies and the 2012 extremeevent ensemble suggest that the mechanisms driving the shift in the lower tail of the precipitation distribution are the same that cause the shift in the mean between 2012 and the baseline.

\section{Counterfactual simulations}

To examine the effect of anthropogenic GHGs on the region's atmospheric circulation in 2012, we calculated the change in ensemble-mean winds from each of the five natural-forcings ensembles to the 2012 all-forcings ensemble. Notable variations in the wind differences among the five natural-forcings scenarios reflect the effects of different SST boundary conditions used in each scenario (Figs. 7b-f). However, all five naturalforcings scenarios share important characteristics. At the 500-hPa level, all scenarios show an anticyclonic change in the winds over CONUS and southern Canada under anthropogenic GHG forcing. Although the strength, shape, and precise location of the anticyclonic change pattern vary among the five scenarios, overall the result of anthropogenic GHG forcing is an intensification of the drought-promoting circulation pattern that prevailed in the 2012 simulations (Fig. 7a). At the $850-\mathrm{hPa}$ level, anthropogenic GHGs lead to an increase in the magnitude of the winds that bring moisture from the Gulf of Mexico to the central United States, although the magnitude varies across the five natural-forcings scenarios (Fig. 8). Therefore, the net effect of anthropogenic GHG-induced wind patterns on higher and lower levels is to suppress precipitation despite increasing atmospheric moisture.

Pooling the natural-forcings scenarios, the net impact of anthropogenic forcing is a statistically significant, but small, $5 \%$ decrease in the ensemble-mean MJJA precipitation over the study region. Across natural-forcings scenarios the impact varies from $2 \%$ to $8 \%$ decrease. It is worth noting that these results appear to contrast with the observational record that shows no indication of anthropogenically driven MJJA precipitation declines in the region (Hoerling et al. 2014). Most stations with records dating back to at least 1917 show no statistically significant linear century-scale trend in summer precipitation, while of those that do show a significant trend ( $\sim 30 \%$ of stations), all have positive trends (De Martino et al. 2013). In general with regards to seasonal precipitation totals over the last century, there is low detectability of trends that are unlikely to have arisen from internal variability alone (Anderson et al. 2015), making observed regional seasonal precipitation trends a very weak metric for testing model fidelity (Rupp et al. 2013a).

Across exceedance probabilities, the all-forcings precipitation deficit is larger than the precipitation deficit from the average of the five natural-forcings scenarios. While there is no indication that the difference between the all-forcings and natural-forcings precipitation decreases with decreasing exceedance probability, the all-forcings ensemble becomes statistically indistinguishable from two of the five natural-forcings ensembles due to sampling uncertainty (Fig. 9a).

Convective inhibition as approximated by $\mathrm{CIN}^{*}$ is also enhanced under anthropogenic forcings (Fig. 9b), 
a)

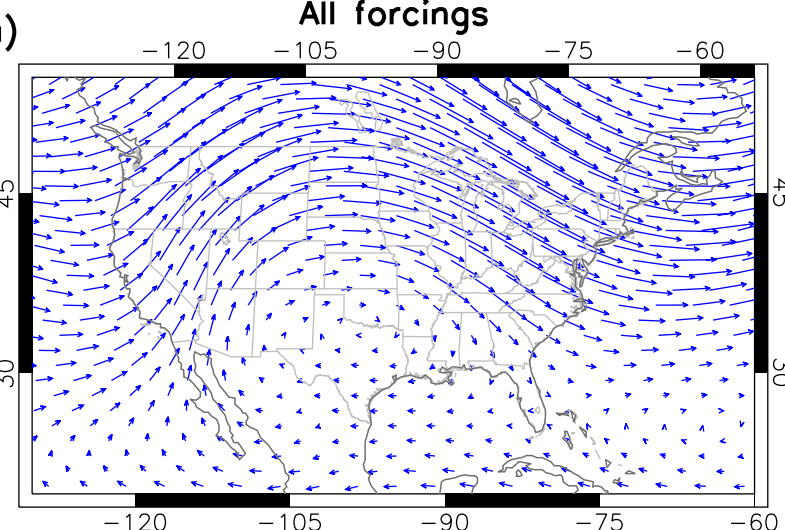

c)
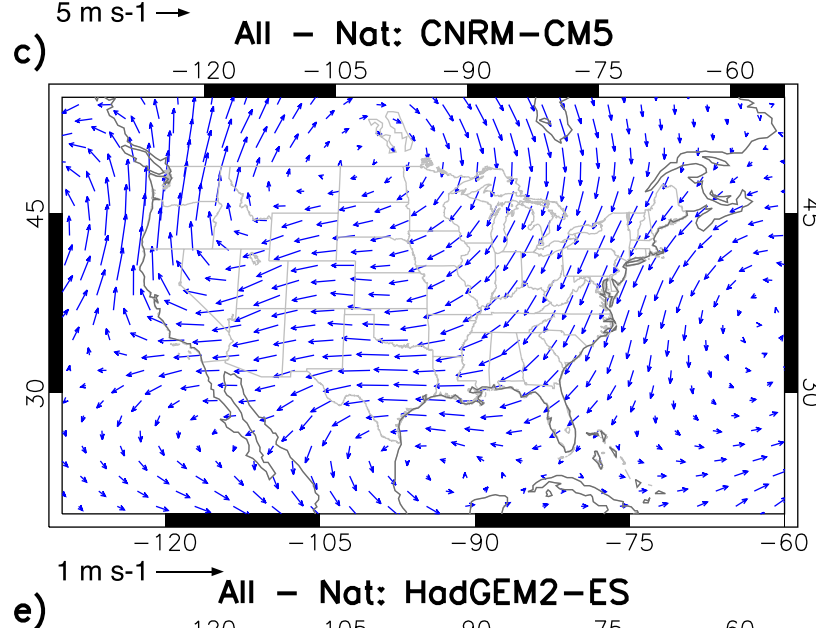

e)

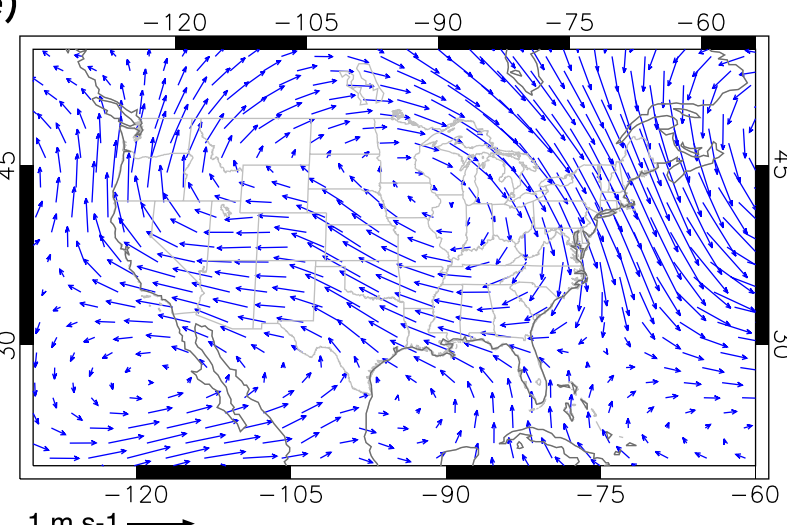

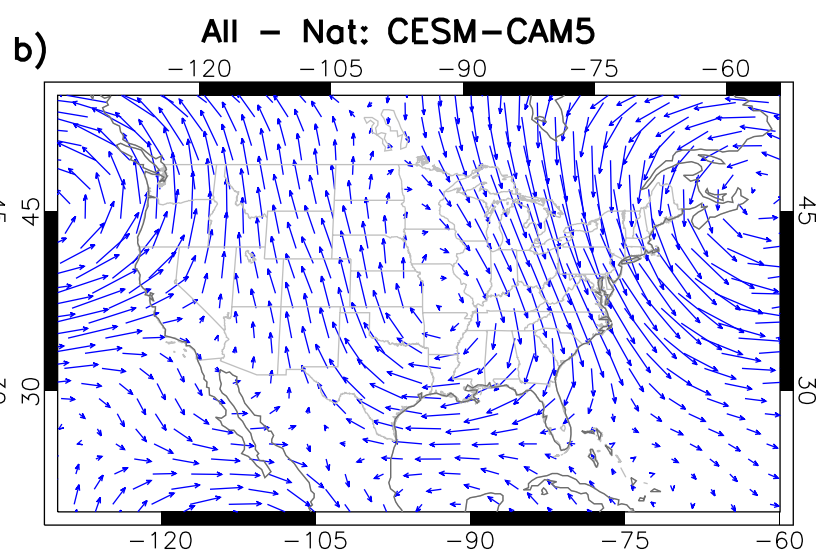

d)

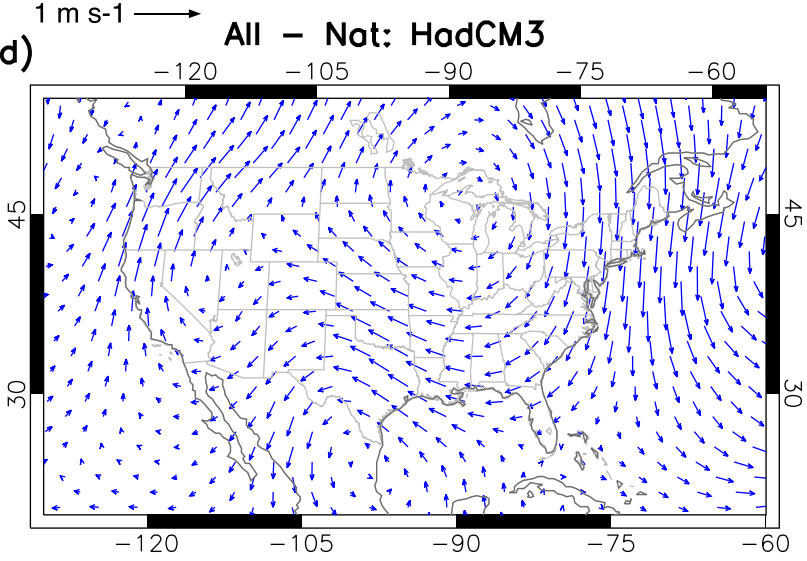

f)

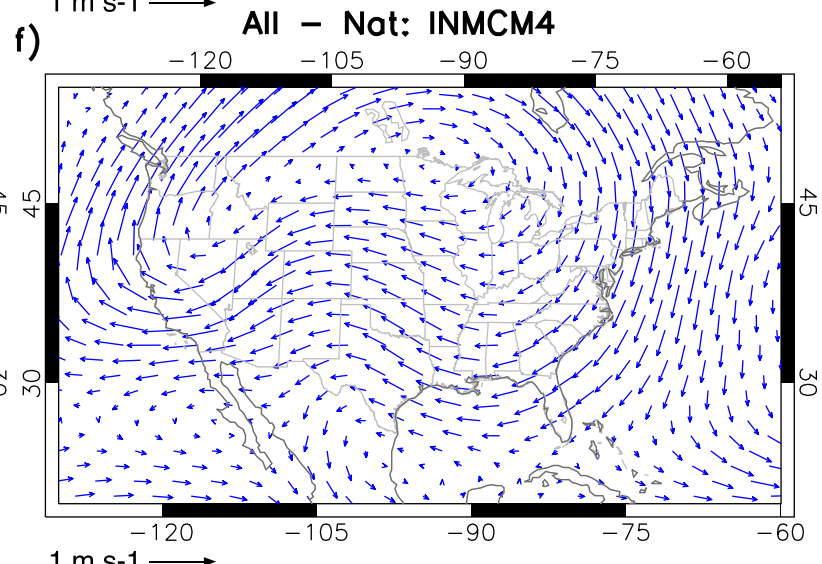

FIG. 7. (a) Ensemble-mean MJJA 2012 500-hPa winds in the all-forcings scenario and (b)-(f) the difference in 500-hPa winds between the ensemble means of each of the five natural-forcings scenarios and the ensemble mean of the all-forcings scenario (All - Nat). Note the scale of the wind vector in (a) is different than the others.

suggesting that the suppression of deep convection is an important factor in the reduction of precipitation. Here we assume that the relationship between CIN and the proxy CIN* under increased GHGs remains effectively unchanged. This assumption merits testing.

Changes in other variables analyzed indicate increased evaporative demand under anthropogenic forcing in MJJA 2012. For example, in the all-forcings ensemble, the vapor pressure deficit is statistically significantly higher than under every natural-forcing scenario for return periods up to about $60 \mathrm{yr}$; beyond $60 \mathrm{yr}$ VPD is also higher in the all-forcings ensemble, but the confidence intervals overlap with at least one natural-forcing scenario (Fig. 9c). Net shortwave radiation is slightly higher ( $\sim 1 \%$ in the mean) under anthropogenic forcing (not shown), and the spatial pattern of change in $10-\mathrm{m}$ wind 

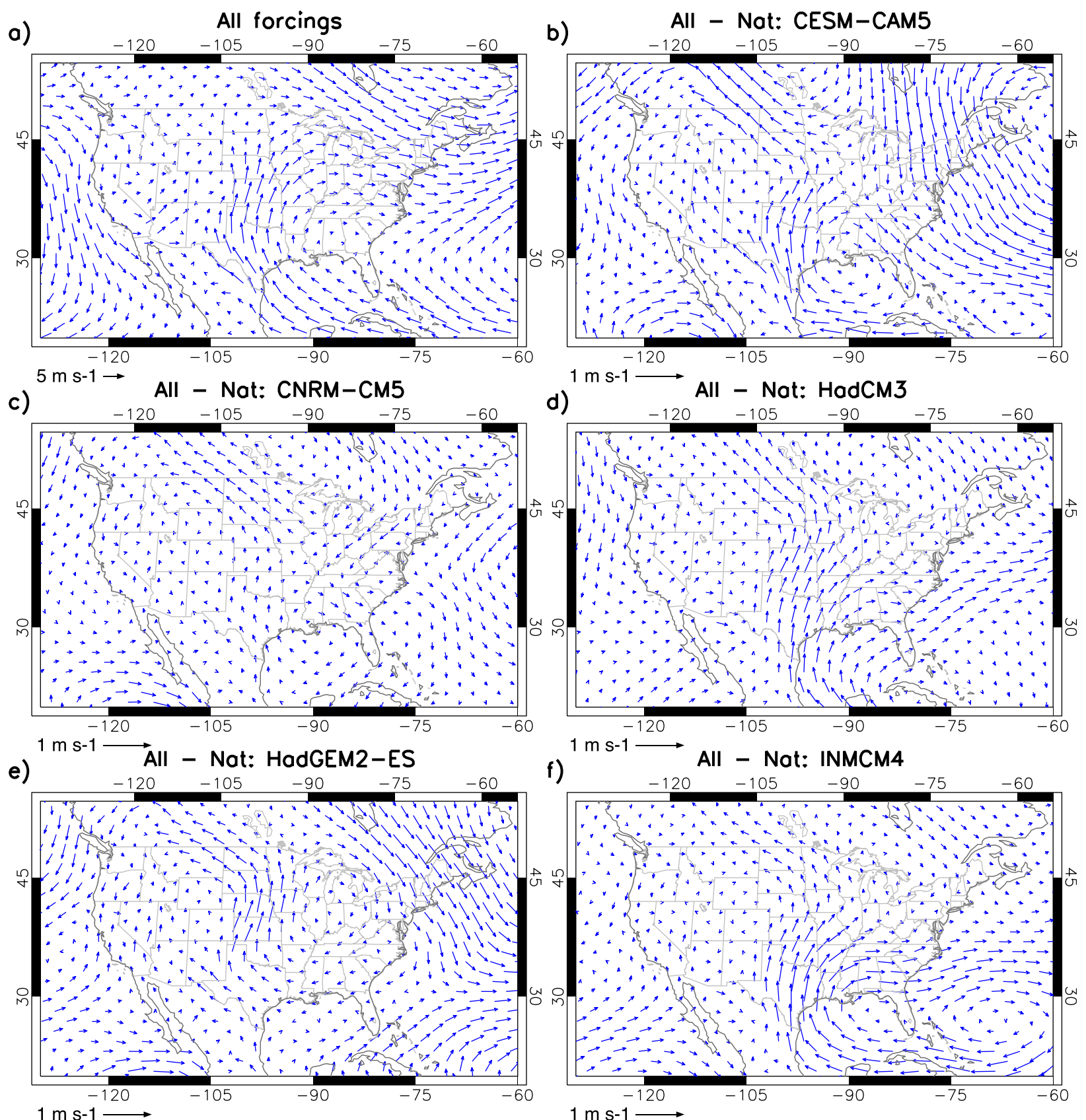

FIG. 8. As in Fig. 7 but for 850 -hPa winds.

velocity (not shown but similar to the 850 -hPa wind patterns in Fig. 8) suggests a small increase in mean wind speed over the Great Plains.

Despite the anthropogenically forced decrease in precipitation and increase in evaporative demand, summer $P-E$ is largely unaffected. Although the all-forcings ensemble mean $P-E$ is slightly lower $(-2 \%)$ than the combined ensemble mean of the natural-forcings scenarios, the lower tail of the all-forcings distribution is not distinguishable from the lower tails of the natural-forcings distributions (Fig. 9d). As discussed in section 3, the reason, in large part, is that when the region approaches a very dry state during summer, $d E / d P$ is close to one; that is, the principal source of water for evapotranspiration is the rainfall that falls at the time, not the preexisting water in the soil. This lack of an effect on $P-E$ is reflected in the simulated soil moisture shown in Fig. 10b, where soil moisture deficits in the all-forcings ensemble have 

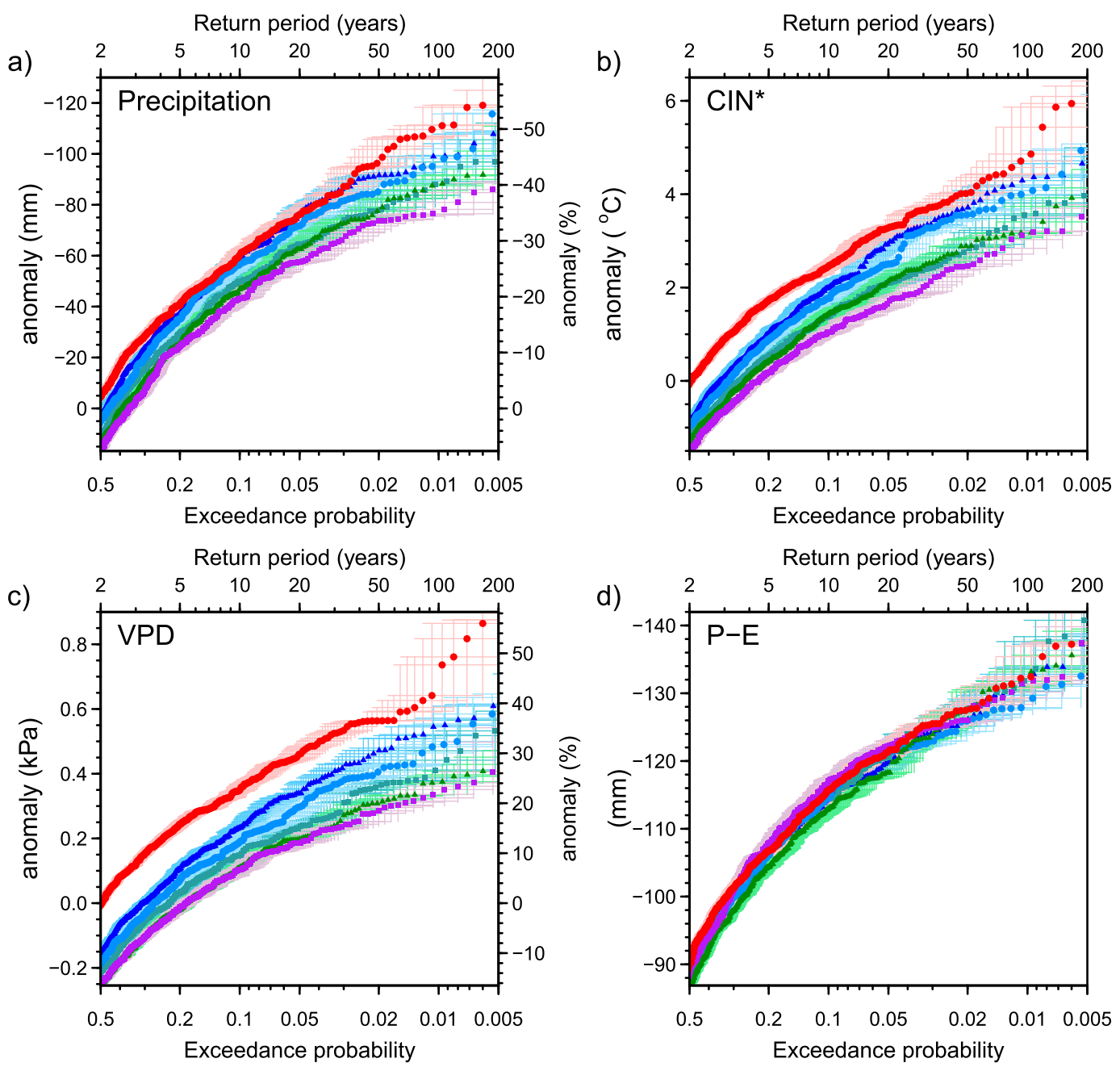

- All forcings

- Nat. forcings: CESM1-CAM5

- Nat. forcings: CNRM-CM5

- Nat. forcings: HadCM3

$\Delta$ Nat. forcings: HadGEM2-ES

- Nat. forcings: INMCM4

FIG. 9. The 2012-ensemble exceedance probabilities for domain-averaged, simulated MJJA (a) precipitation anomalies, (b) CIN* anomalies, (c) VPD anomalies, and (d) $P-E$ from the all-forcings scenario and the five natural-forcings scenarios. Anomalies are differences from the 2012 all-forcings ensemble mean. Thin vertical and horizontal line segments about each point show bootstrapped $90 \%$ confidence intervals.

exceedance probabilities that fall within the ranges seen across the natural-forcings scenario. It is also worth noting that, though precipitation is less in the all-forcings MJJA, precipitation is marginally higher during the preceding cold-season months of January-April $(+2.3 \%)$, so soil moisture at the onset of summer is marginally higher under all forcings relative to natural forcings.

Another important control on $P-E$ is the inverse relationship between stomatal conductance and atmospheric $\mathrm{CO}_{2}$ concentration as simulated by MOSES1 [see Eq. (15) in Cox et al. 1999]. The 38\% increase in $\mathrm{CO}_{2}$ from 1850 to 2012 corresponds to as much as a $28 \%$ decrease in stomatal conductance (and potentially up to the same percent reduction in transpiration), countering the effect of increased vapor pressure deficit and direct effects of increased temperature.

How anthropogenic GHGs affect the likelihood of certain drought-relevant extremes in 2012 is summarized in Fig. 11, where the natural-forcings simulations have been pooled into a single sample. For example, the $0.02 \mathrm{ex}$ ceedance probability (i.e., 1 in $50 \mathrm{yr}$ ) MJJA temperature under preindustrial forcing is about 20 times more likely to be surpassed in 2012. Likewise, the 0.02 exceedance probability MJJA precipitation deficit is roughly 3 times as likely to be exceeded in 2012. In contrast, metrics of water storage $(P-E$ and soil moisture content) are largely unaffected. 

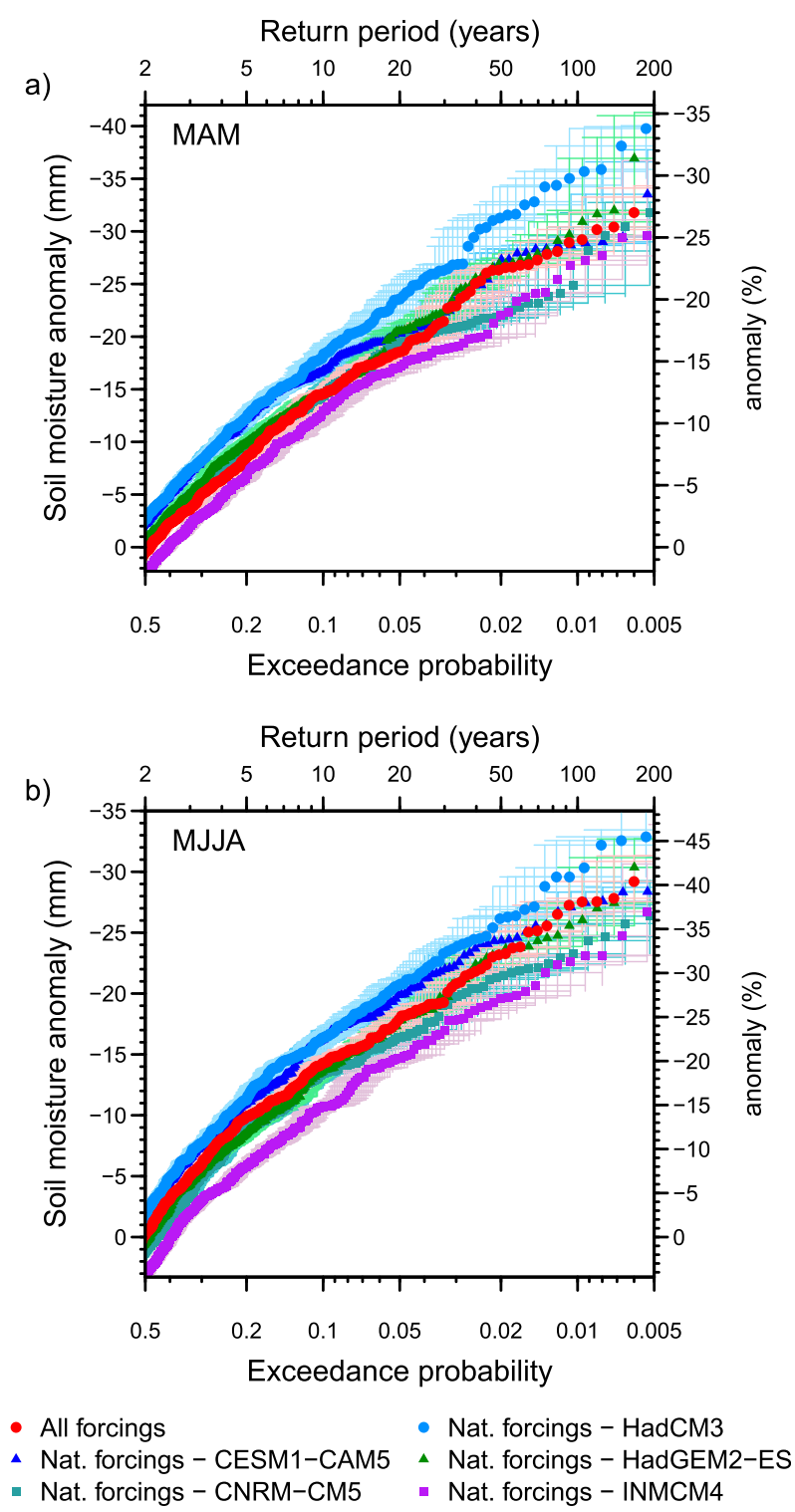

FIG. 10. As in Fig. 9, but for (a) MAM and (b) MJJA soil moisture deficits.

Uncertainty in how well our natural SST patterns represent the absence of anthropogenic influence contributes to the total uncertainty of the above results. As noted in section 2, the delta SST patterns contain both anthropogenically induced response and internal variability. Some delta SST patterns have conspicuous features, such as the negative-phase PDO-like patterns from CESM1-CAM5.1-FV2 and HadGEM2-ES, and the La Niña pattern from HadGEM2-ES (Fig. S1). The North Pacific spatial variability in the delta SSTs from CESM1-CAM5.1-FV2, for example, could have arisen largely by chance, and imposing these delta SSTs on to the 2012 negative-phase PDO-like pattern shown in
Figs. S2a-c would lead to an amplified negative-phase PDO pattern in the natural-forcings SSTs (Figs. S2d-f). Non-GHG external forcings such aerosols, through their interactions with clouds, can also affect the magnitude and spatial variability of surface temperature changes; inconsistencies with observations have been attributed to how well CMIP5 GCMs simulate aerosol forcing [see Zhang et al. (2013) for HadGEM2-ES in particular; Ekman 2014; Seinfeld et al. 2016].

To examine the effect on the pooled results of the delta SSTs with the most conspicuous patterns in the Pacific Ocean, we excluded first CESM1-CAM5.1-FV2 and then both CESM1-CAM5.1-FV2 and HadGEM2-ES from the pooled simulations and recalculated the natural-forcings exceedance probabilities of the variables shown in Fig. 11 (Figs. S5 and S6). In both cases, there is effectively no change in the calculated exceedance probabilities of the hydroclimatic variables in MJJA, while excluding CESM1-CAM51-FV2 only marginally decreases naturalforcings MJJA temperatures in the study region.

Uncertainty also arises from the particular GCM (HadAM3P) we used to simulate the water cycle in the atmosphere and land. Biases in HadAM3P can affect the strength of a response, particularly when relationships are nonlinear. HadAM3P has warm and dry summer biases over the central United States (Fig. 12b; see also Rupp et al. 2013b, 2015). HadAM3P generates too much precipitation in MAM $(+33 \%)$ and too little in MJJA $(-24 \%)$, although the year to year variability in simulated MJJA precipitation is close to observed: the ratio of simulated to observed standard deviation is nearly 1 (0.99). [We point out that NCEP generates MJJA precipitation amounts similar to HadAM3P (Fig. S3) and thus also has a large bias relative to station observations.]

For summer at least, the bias in precipitation probably explains most of the bias in temperature given that in summer there is a strong association of precipitation with temperature through changes in cloud cover, soil moisture, and the energy budget (e.g., Klein et al. 2006; Seager et al. 2014; Yin et al. 2014). The causes of the summer precipitation bias are not known and may be related to shortcomings in the deep convection parameterization (Prein et al. 2015), the strength of land surface-atmosphere coupling (Koster et al. 2004), and/ or other factors. Determining exact causes is difficult (Klein et al. 2006) and outside the focus of this study.

Irrespective of the underlying causes, we may speculate on the impact of the biases. For one, these summertime biases imply that evapotranspiration is too much supply-limited, that is, going far to the lower left along the $E$ versus $P$ curve in Fig. 5, where a change in $P$ is nearly matched by an equal change in $E$ and small changes in temperature (on the order of $1^{\circ} \mathrm{C}$ ) have 
a)

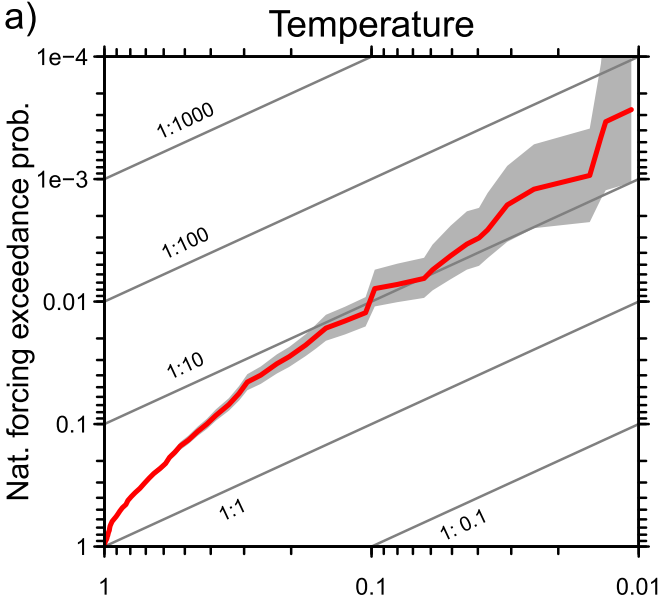

All forcing exceedance prob.

c)

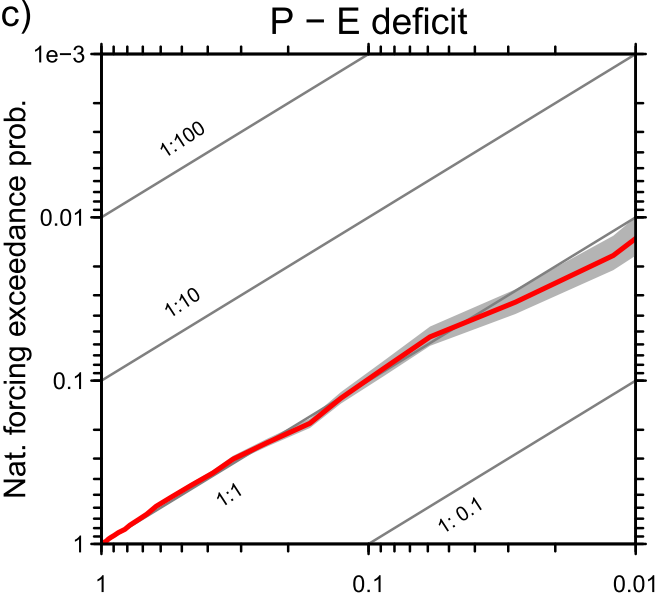

All forcing exceedance prob. b)

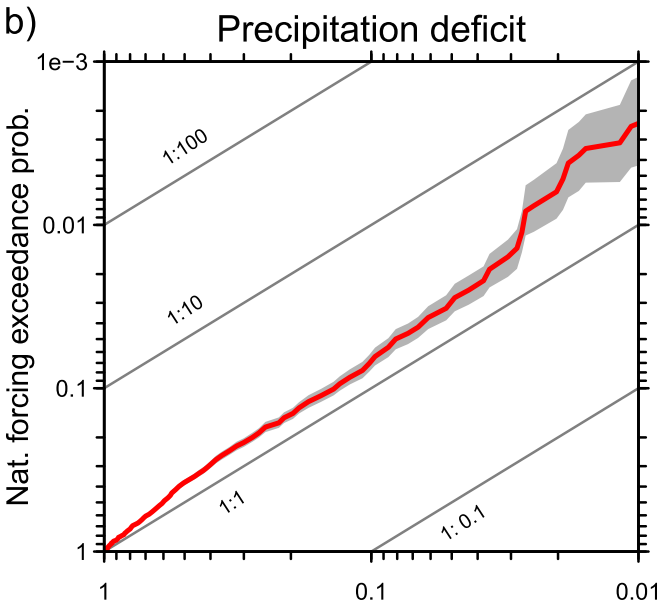

All forcing exceedance prob.

d)

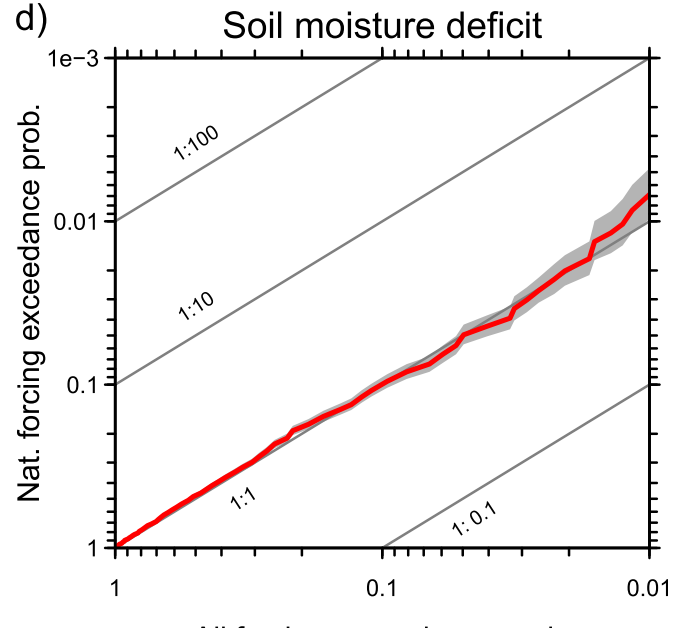

All forcing exceedance prob.

FIG. 11. Exceedance probability in the pooled natural-forcings scenarios against exceedance probability in the all-forcings scenario for equivalent values of the MJJA 2012 (a) temperature, (b) precipitation deficit, (c) $P-E$ deficit, and (d) soil moisture deficit. The shaded area shows the inner 95th percentile of bootstrapped estimates.

essentially no impact. This could lead to an underprediction of the response in evapotranspiration to increased temperature, and an overprediction in the response in evapotranspiration to forced changes in precipitation, with therefore little effect on $P-E$ and soil moisture. In other words, part of why HadAM3P does not simulate a decline in summer 2012 soil moisture due to anthropogenic forcing may be because it generates too little summertime precipitation in general.

The negligible modeled response of soil moisture may also be linked to the representation of soil moisture storage and resistance to evapotranspiration demand. Although we recommend a regional evaluation of soil moisture dynamics in HadAM3P, we cannot do a truly fair assessment of the simulated plant-available soil moisture using observed soil moisture, or even using soil moisture from available reanalysis datasets such as the North American Land Data Assimilation System phase 2 (NLDAS-2; Xia et al. 2012) because of the mismatch in the variable saved. In NLDAS-2, soil moisture in the top $1 \mathrm{~m}$ is the archived soil moisture variable common to all three of its land surface models. In HadAM3P, plants draw soil moisture from the top $1 \mathrm{~m}$ of soil if grasses and $3 \mathrm{~m}$ if forests, weighted by an exponential root density functions; therefore, variability over the entire root zone will be dominated by the upper $1 \mathrm{~m}$ due to transpiration, evaporation, and percolation out of the top $1 \mathrm{~m}$. Focusing on periods of soil moisture deficit, the frequency distribution of HadAM3P soil moisture anomalies is consistent with those from the two (of three) betterperforming [according to Xia et al. (2014)] NLDAS-2 models (Fig. S7). Therefore, HadAM3P at least appears 
a) MAM

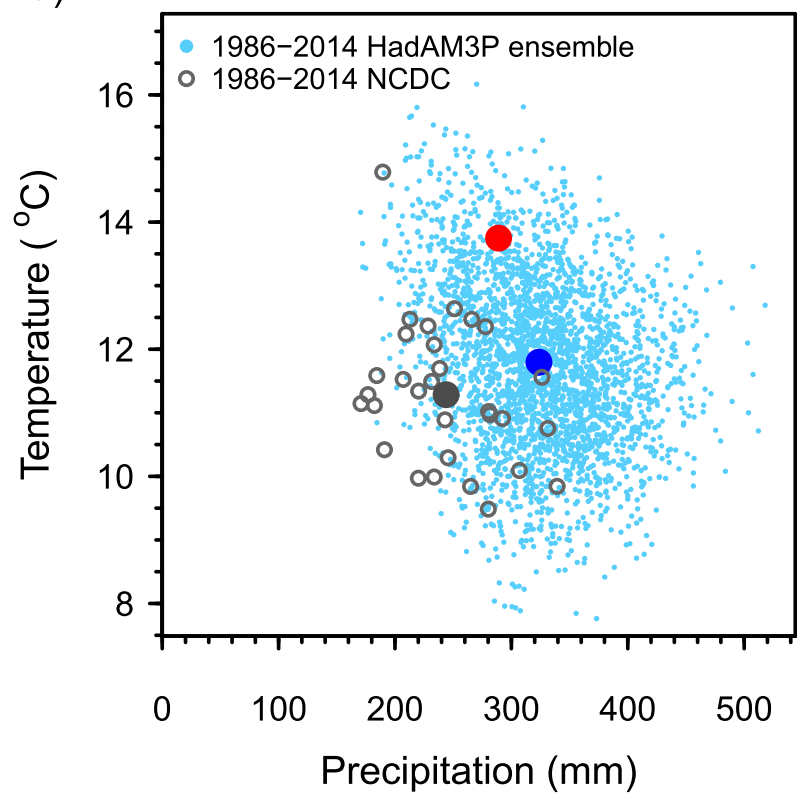

b)

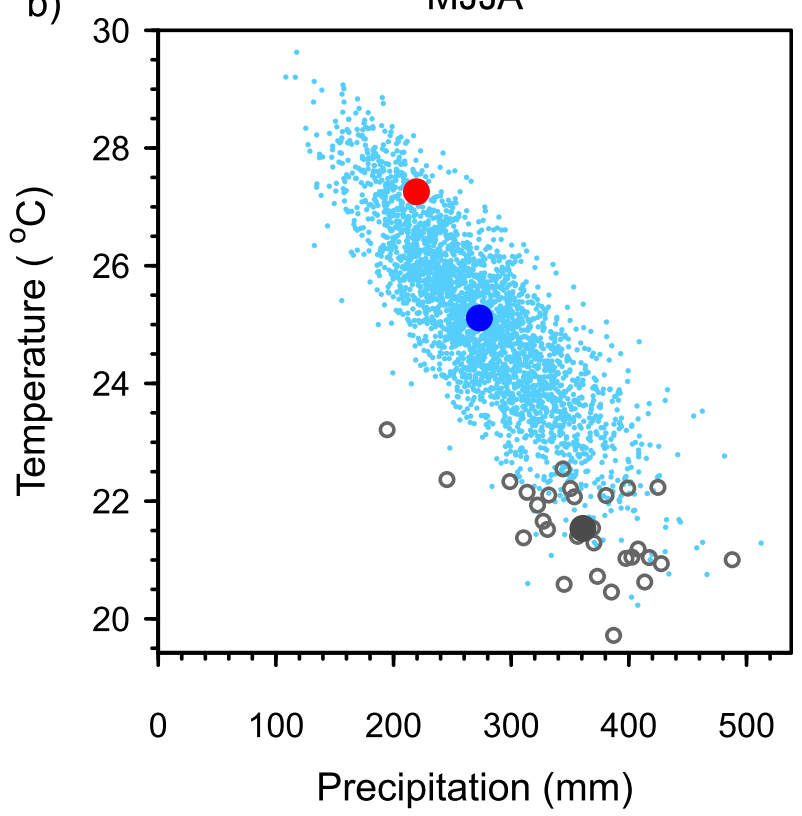

FIG. 12. Domain-averaged 1986-2014 observed (NCDC and simulated (HadAM3P) seasonal temperature vs precipitation for (a) MAM and (b) MJJA. The large circles show the mean of the observations (gray), 1986-2014 ensemble (blue), and 2012 ensemble (red).

comparable to the state-of-the-art in large-scale soil moisture monitoring, although that in itself is not an indicator of good performance. We note that Xia et al. (2014) found that all NLDAS-2 models simulated less soil moisture than observed in the Midwest because they (like HadAM3P) did not include irrigation.

\section{Conclusions}

A large ensemble of climate model simulations allows us to estimate how much the particular SST boundary conditions and forcings in 2012 alter the likelihood of extreme drought in the central United States during that year's summer relative to the likelihood of extreme drought during the last few decades. MJJA precipitation and soil moisture in any single ensemble member of 2012 is likely to be below average, where average is defined by a 1986-2014 baseline period. As an example of the effect on extreme values, the 0.02 exceedance probability MJJA precipitation deficit-as calculated from the baseline period-corresponds to only a $0.1 \mathrm{ex}-$ ceedance probability in 2012. In other words, that particular deficit is about 5 times as likely to be exceeded in 2012 relative to the recent past. The 0.02 exceedance probability MJJA soil moisture deficit is about 6 times as likely to be exceeded in 2012, although the summer soil moisture deficits in 2012 are largely the carry-over of the soil moisture deficits in the spring, owing to both increased evapotranspiration (driven by anomalously high temperatures) and decreased precipitation in spring 2012. Although natural and anthropogenic effects are not fully separable in this numerical experiment, we conclude that the differences in likelihood are driven primarily by the spatiotemporal pattern of SSTs in 2012 that arose from internal variability and much less so by higher anthropogenic GHG concentrations, relative to the 1986-2014 baseline.

Based on these simulations, it could be said that SST anomalies created favorable conditions for a heat wave flash drought in early summer of 2012, such as Mo and Lettenmaier (2015) assert did occur that year. Moreover, the simulations suggest that SSTs contributed to the drought during the remainder of the summer by promoting high pressure ridging over the Great Plains that suppressed rainfall. From the large ensemble of simulations, we can estimate the portion of a precipitation deficit attributable to the imposed boundary conditions. For example, to a $-45 \%$ MJJA precipitation anomaly in 2012 there is roughly a two-thirds contribution from system internal variability and a one-third contribution from the 2012 SST boundary conditions - which in turn have a small anthropogenic component. This estimate is made by comparing the precipitation anomaly in 2012 $(-45 \%)$ with that for the baseline period $(-30 \%)$ at the same exceedance probability (Fig. 4a). This contribution from SST anomalies is notably larger than found by Hoerling et al. (2014) and Wang et al. (2014), exemplifying how much results can vary across climate models.

Being able to predict extreme summer drought in the central United States has been a challenge because variability in summer precipitation arises largely from 
internal variability in the atmosphere, and SSTs have not seemed to offer much predictive power. Hoerling et al. (2014), for example, showed only a weak linear correlation between summer Great Plains rainfall and summer SST anomalies in the observed record. Other studies have noted that U.S. hydroclimate is sensitive to Pacific SSTs during the cold season (e.g., Hoerling and Kumar 2003) and sensitive in summer to both Atlantic SSTs (e.g., Schubert et al. 2009; Findell and Delworth 2010, Kushnir et al. 2010) and northern midlatitude Pacific SSTs (McKinnon et al. 2016), suggesting that methods other than linear correlation analysis may reveal advantageous relationships, particularly if the target is extreme events. While this study has not been about summer drought forecasting per se, the notable influence of SSTs on precipitation and temperature in spring and summer of 2012 within the simulations presented here implies that large-ensemble forecasts with some skill can be made from forecasts of SSTs used as boundary conditions in models with demonstrated hindcast skill.

A second set of numerical experiments isolates the effect of anthropogenic forcings $\left(\mathrm{GHGs}, \mathrm{O}_{3}\right.$, and $\mathrm{SO}_{2}$ ) on the likelihood or magnitude of extreme drought. Cast in terms of likelihood, extreme summer precipitation deficits (i.e., those with a 1 -in-50 to 1 -in-100 probability of being exceeded in MJJA 2012 under preindustrial forcings) are roughly 3 to 4 times more likely to be exceeded under 2012-level anthropogenic forcings. In terms of changing magnitudes, anthropogenic forcing increases these precipitation deficits associated with these probabilities deficits by $19 \%$ and $23 \%$, respectively.

Anthropogenic forcings also enhance evaporative demand in MJJA 2012, yet MJJA-average soil moisture is largely unaffected. This may at first seem counterintuitive, yet evapotranspiration is reduced by nearly the same amount as precipitation because the evapotranspiration in summer 2012 is strongly supply-limited. Care should therefore be taken with the interpretation of the marginal change in soil moisture due to anthropogenic forcings. It does not imply that there is no change in the detrimental impacts of drought. There is still a decrease in water available to plants and, with the closure of stomata under water stress, a reduction of $\mathrm{CO}_{2}$ uptake, resulting in less photosynthesis. At the same time, higher $\mathrm{CO}_{2}$ levels lead to increased photosynthesis for the same amount of water transpired, countering to some degree the effect of a decreased water supply.

The absence of change in large soil moisture deficits also implies that $P-E$ and soil moisture during summer drought in the central United States are not very useful metrics within the simulations for gauging anthropogenic GHG influence and its agricultural and ecological impacts. In these simulations, precipitation alone is the more meaningful metric, while other metrics such as net primary production would measure more directly the impacts on agricultural lands and other ecosystems.

Acknowledgments. The work was funded by the National Institute of Food and Agriculture (NIFA), U.S. Department of Agriculture (USDA), Agriculture and Food Research Initiative Grant 2014-35102-21830. Sihan Li received additional support from NIFA, USDA, under Award 2011-68002-30191. Neil Massey was supported by the EUCLEIA project funded by the European Union's Seventh Framework Programme (FP7/2007-2013) under Grant Agreement 607085. The authors thank Darrin Sharp for assisting with data management, Andy Bowery, Jonathan Miller, Friederike Otto, and Myles Allen of Climateprediction.net, the thousands of volunteers who supplied the computing power for this study, and two anonymous reviewers for their insightful comments and suggestions. Climateprediction.net uses The Berkeley Open Infrastructure for Network Computing (BOINC), which is supported by the National Science Foundation through Awards SCI-0221529, SCI-0438443, SCI0506411, PHY/0555655, and OCI-0721124. The simulations generated for this paper are available by request from the corresponding author.

\section{REFERENCES}

Anderson, B. T., D. J. Gianotti, and G. D. Salvucci, 2015: Detectability of historical trends in station-based precipitation characteristics over the continental United States. J. Geophys. Res. Atmos., 120, 4842-4859, doi:10.1002/2014JD022960.

Boucher, O., and Coauthors, 2013: Clouds and aerosols. Climate Change 2013: The Physical Science Basis, T. F. Stocker et al., Eds., Cambridge University Press, 571-657.

Cox, P. M., R. A. Betts, C. B. Bunton, R. L. H. Essery, P. R. Rowntree, and J. Smith, 1999: The impact of new land surface physics on the GCM simulation of climate and climate sensitivity. Climate Dyn., 15, 183-203, doi:10.1007/s003820050276.

De Martino, G., N. Fontana, G. Marini, and V. P. Sing, 2013: Variability and trend in seasonal precipitation in the continental United States. J. Hydrol. Eng., 18, 630-640, doi:10.1061/ (ASCE)HE.1943-5584.0000677.

Dingman, S. L., 2002: Physical Hydrology. 2nd ed. Prentice-Hall, $646 \mathrm{pp}$

Donlon, C. J., M. Martin, J. Stark, J. Roberts-Jones, E. Fiedler, and W. Wimmer, 2012: The Operational Sea Surface Temperature and Sea Ice Analysis (OSTIA) system. Remote Sens. Environ., 116, 140-158, doi:10.1016/j.rse.2010.10.017.

Ekman, A. M. L., 2014: Do sophisticated parameterizations of aerosol-cloud interactions in CMIP5 models improve the representation of recent observed temperature trends? J. Geophys. Res. Atmos., 119, 817-832, doi:10.1002/2013JD020511.

Findell, K. L., and T. L. Delworth, 2010: Impact of common sea surface temperature anomalies on global drought and pluvial frequency. J. Climate, 23, 485-503, doi:10.1175/2009JCLI3153.1.

Forster, P. M., T. Andrews, P. Good, J. M. Gregory, L. S. Jackson, and M. Zelinka, 2013: Evaluating adjusted forcing and model 
spread for historical and future scenarios in the CMIP5 generation of climate models. J. Geophys. Res. Atmos., 118, 11391150, doi:10.1002/jgrd.50174.

Gordon, C., C. Cooper, C. A. Senior, H. Banks, J. M. Gregory, T. C. Johns, J. F. B. Mitchell, and R. A. Wood, 2000: The simulation of SST, sea ice extents and ocean heat transports in a version of the Hadley Centre coupled model without flux adjustments. Climate Dyn., 16, 147-168, doi:10.1007/s003820050010.

Hoerling, M. P., and A. Kumar, 2003: The perfect ocean for drought. Science, 299, 691-694, doi:10.1126/science.1079053.

, J. Eischeid, A. Kumar, R. Leung, A. Mariotti, K. Mo, S. Schubert, and R. Seager, 2014: Causes and predictability of the 2012 Great Plains drought. Bull. Amer. Meteor. Soc., 95, 269-282, doi:10.1175/BAMS-D-13-00055.1.

Kalnay, E., and Coauthors, 1996: The NCEP/NCAR 40-Year Reanalysis Project. Bull. Amer. Meteor. Soc., 77, 437-471, doi:10.1175/1520-0477(1996)077<0437:TNYRP > 2.0.CO;2.

Klein, S. A., X. Jiang, J. Boyle, S. Malyshev, and S. Xie, 2006: Diagnosis of the summertime warm and dry bias over the U.S. Southern Great Plains in the GFDL climate model using a weather forecasting approach. Geophys. Res. Lett., 33, L18805, doi:10.1029/2006GL027567.

Koster, R. D., and Coauthors, 2004: Regions of coupling between soil moisture and precipitation. Science, 305, 1138-1140, doi:10.1126/science.1100217.

Kushnir, Y., R. Seager, M. Ting, N. Naik, and J. Nakamura, 2010: Mechanisms of tropical Atlantic influence on North American hydroclimate variability. J. Climate, 23, 5610-5628, doi:10.1175/2010JCLI3172.1.

Massey, N., and Coauthors, 2014: weather@home-Development and validation of a very large ensemble modelling system for probabilistic event attribution. Quart. J. Roy. Meteor. Soc., 141, 1528-1545, doi:10.1002/qj.2455.

McKinnon, K. A., A. Rhines, M. P. Tingley, and P. Huybers, 2016: Long-lead predictions of eastern United States hot days from Pacific sea surface temperatures. Nat. Geosci., 9, 389-394, doi:10.1038/ngeo2687.

Meinshausen, M., and Coauthors, 2011: The RCP greenhouse gas concentrations and their extensions from 1765 to 2300 . Climatic Change, 109, 213-241, doi:10.1007/s10584-011-0156-z.

Mo, K. C., and D. P. Lettenmaier, 2015: Heat wave flash droughts in decline. Geophys. Res. Lett., 42, 2823-2829, doi:10.1002/ 2015 GL064018.

Mote, P. W., M. R. Allen, R. G. Jones, S. Li, R. Mera, D. E. Rupp, A. Salahuddin, and D. Vickers, 2015: Superensemble regional climate modeling for the western United States. Bull. Amer. Meteor. Soc., 97, 203-215, doi:10.1175/BAMS-D-14-00090.1.

Myoung, B., and J. W. Nielsen-Gammon, 2010a: Sensitivity of monthly convective precipitation to environmental conditions. J. Climate, 23, 166-188, doi:10.1175/2009JCLI2792.1.

— and - 2010b: The convective instability pathway to warm season drought in Texas. Part I: The role of convective inhibition and its modulation by soil moisture. J. Climate, 23, 4461-4473, doi:10.1175/2010JCLI2946.1.

NCDC, 2016: Billion-dollar weather and climate disasters. [Available online at http://www.ncdc.noaa.gov/billions.]

Pope, V., M. Gallani, P. Rowntree, and R. Stratton, 2000: The impact of new physical parameterizations in the Hadley Centre climate model: HadAM3. Climate Dyn., 16, 123-146, doi:10.1007/s003820050009.

Prein, A. F., and Coauthors, 2015: A review on regional convection-permitting climate modeling: Demonstrations, prospects, and challenges. Rev. Geophys., 53, 323-361, doi:10.1002/2014RG000475.
Rayner, N. A., D. E. Parker, E. B. Horton, C. K. Folland, L. V. Alexander, D. P. Rowell, E. C. Kent, and A. Kaplan, 2003: Global analyses of sea surface temperature, sea ice, and night marine air temperature since the late nineteenth century. J. Geophys. Res., 108, 4407, doi:10.1029/2002JD002670.

Rupp, D. E., J. T. Abatzoglou, K. C. Hegewisch, and P. W. Mote, 2013a: Evaluation of CMIP5 20th century climate simulations for the Pacific Northwest USA. J. Geophys. Res., 188, 10884 10 906, doi:10.1002/jgrd.50843.

_ , P. W. Mote, N. Massey, F. E. L. Otto, and M. R. Allen, 2013b: Human influence on the probability of low precipitation in the central United States in 2012 [in "Explaining Extreme Events of 2012 from a Climate Perspective"]. Bull. Amer. Meteor. Soc., 94, S2-S6, doi:10.1175/BAMS-D-13-00085.1.

, S. Li, N. Massey, S. N. Sparrow, P. W. Mote, and M. R. Allen, 2015: Anthropogenic influence on the changing likelihood of an exceptionally warm summer in Texas, 2011. Geophys. Res. Lett., 42, 2392-2400, doi:10.1002/2014GL062683.

Schaller, N. S., F. E. L. Otto, G. J. van Oldenborgh, N. R. Massey, S. Sparrow, and M. R. Allen, 2014: The heavy precipitation event of May-June 2013 in the upper Danube and Elbe basins [in "Explaining Extreme Events of 2012 from a Climate Perspective"']. Bull. Amer. Meteor. Soc., 95, S69-S72, doi:10.1175/ BAMS-D-13-00085.1.

Schubert, S. D., and Coauthors, 2009: A U.S. CLIVAR project to assess and compare the responses of global climate models to drought-related SST forcing patterns: Overview and results. J. Climate, 22, 5251-5272, doi:10.1175/2009JCLI3060.1.

Seager, R., L. Goddard, J. Nakamura, N. Henderson, and D. E. Lee, 2014: Dynamical causes of the 2010/11 Texas-northern Mexico drought. J. Hydrometeor., 15, 39-68, doi:10.1175/ JHM-D-13-024.1.

Seinfeld, J. H., and Coauthors, 2016: Improving our fundamental understanding of the role of aerosol-cloud interactions in the climate system. Proc. Natl. Acad. Sci. USA, 113, 5781-5790, doi:10.1073/pnas.1514043113.

Smith, A., and J. Matthews, 2015: Quantifying uncertainty and variable sensitivity within the U.S. billion-dollar weather and climate disaster cost estimates. Nat. Hazards, 77, 1829-1851, doi:10.1007/s11069-015-1678-x.

Taylor, K. E., R. J. Stouffer, and G. A. Meehl, 2012: An overview of CMIP5 and the experiment design. Bull. Amer. Meteor. Soc., 93, 485-498, doi:10.1175/BAMS-D-11-00094.1.

Wang, H., S. Schubert, R. Koster, Y.-G. Ham, and M. Suarez, 2014: On the role of SST forcing in the 2011 and 2012 extreme U.S. heat and drought: A study in contrasts. J. Hydrometeor., 15, 1255-1273, doi:10.1175/JHM-D-13-069.1.

Xia, Y., and Coauthors, 2012: Continental-scale water and energy flux analysis and validation for the North American Land Data Assimilation System project phase 2 (NLDAS-2): 1. Intercomparison and application of model products. J. Geophys. Res., 117, D03109, doi:10.1029/2011JD016048.

_ _ J. Sheffield, M. B. Ek, J. Dong, N. Chaney, H. Wei, J. Meng, and E. F. Wood, 2014: Evaluation of multi-model simulated soil moisture in NLDAS-2. J. Hydrol., 512, 107-125, doi:10.1016/j.jhydrol.2014.02.027.

Yin, D., M. L. Roderick, G. Leech, F. Sun, and Y. Huang, 2014: The contribution of reduction in evaporative cooling to higher surface air temperatures during drought. Geophys. Res. Lett., 41, 7891-7897, doi:10.1002/2014GL062039.

Zhang, R., and Coauthors, 2013: Have aerosols caused the observed Atlantic multidecadal variability? J. Atmos. Sci., 70, 1135-1144, doi:10.1175/JAS-D-12-0331.1. 